\title{
El negocio internacional de espárrago en el Perú
}

\author{
Jaime de Pablo V., Miguel Ángel Giacinti B., Valentín Tassile \\ y Luisa Fernanda Saavedra
}

RESUMEN

Mediante diversas metodologías, como el índice de competitividad de comercio exterior, el índice de política comercial y la matriz de competitividad TradeCAN, se verifica un proceso de adaptación a los cambios del comercio mundial en el período 2002 a 2012, que se enmarca en el denominado "sistema complejo adaptativo" como transición de la cuarta a la quinta revolución tecnológica en el espárrago en fresco exportado desde el Perú. El mapa de competitividad del Perú permite señalar que esta no es global a nivel internacional, sino más bien parcial o regional. México es el principal competidor, con ventajas comparativas — debido a la paridad real de su moneda frente al dólar estadounidense - en relación con el Perú, pero existen desafíos que deben sortearse a mediano plazo en este proceso de adaptación al cambio.

PALABRAS CLAVES

CLASIFICACIÓN JEL

AUTORES
Perú, exportaciones, espárragos, competitividad, comercio exterior, política comercial, Estados Unidos, Europa, estadísticas comerciales

F14, Q13, Q17

Jaime de Pablo V. es profesor titular de la Universidad de Almería (España), Departamento de Economía y Empresas, Área de Economía Aplicada.jdepablo@ual.es

Miguel Ángel Giacinti B. es titular responsable de la consultora Gabinete MAG (Argentina). miguel.giacinti@gabinetemag.com

Valentín Tassile es profesor adjunto regular de la Universidad Nacional del Comahue (Argentina), Facultad de Ciencias Agrarias, Departamento de Estadística. vtassile@gmail.com

Luisa Fernanda Saavedra es socio gerente de Quality Control Fresh Fruit sAc. 1saavedra@qcfreshfruit.com 


\section{I}

\section{Introducción}

Las revoluciones industriales se vinculan a las periodizaciones de las ondas largas de Kondratieff, como es destacado en varios trabajos de investigación, entre ellos los de Martínez Sánchez (2001) y Jijena (2003). De esta teoría derivaron con posterioridad las ondas cortas de Kitchin (3 años), las de Kuznets (5 años) y las de Juglar (15 años). Todas estas ondas se refieren a procesos de innovación e incorporación de nuevas áreas productivas, que van impulsando el crecimiento hacia la expansión. Kondratieff plantea que cada revolución tecnológica da origen a un ciclo económico largo de aproximadamente 50 años, de los cuales 25 años son de "auge" y los otros 25 años de "crisis". Schumpeter (1944) hace uso de series temporales para el estudio de las crisis cíclicas. Todas corresponden a fases de ajuste, mejoramiento o progresos incrementales en las tecnologías que forjan el crecimiento económico.

Particularmente, en la cuarta revolución tecnológica durante el período de la segunda posguerra mundial es donde se origina la mayor construcción de organizaciones para administrar el comercio en el mundo. Sin embargo, el actual escenario global de crisis y la recesión económica desde el año 2008 marcan el inicio de la quinta revolución tecnológica. Este nuevo escenario implica un cambio de paradigmas en relación con la cuarta revolución, a saber: i) a nivel de recursos básicos: de energía barata y abundante a información y conocimientos ágiles y estratégicos; ii) producción: de automatizada a flexible; iii) mezcla de productos: de estable y homogénea a variada y cambiante; iv) habilidades: de especialización a múltiples capacidades; v) estructura organizativa: de jerárquica y departamental a horizontal y en redes; vi) relaciones laborales: de resolución de conflictos a negociación y cooperación; vii) mercados: de masivos y homogéneos a segmentados y cambiantes; viii) competitividad: de estática a dinámica, y ix) gestión: de costos a gestión.

También hay que resaltar que la quinta revolución es la primera que contiene a la agricultura en la denominada era de la recuperación de los precios internacionales de los alimentos. Los precios reales del comercio verifican una mejora continua desde el año 2000 en adelante —en comparación con los datos desde 1961 — tanto en soja, trigo, maíz, aceite de soja, café tostado, vino, mosto de uva, bebidas no alcohólicas, carnes ovina y bovina, además de pollo y cerdo, como en frutas frescas y jugos concentrados. En el caso de los vegetales, al analizar por medio del ajo, la cebolla, el tomate y el espárrago, se observa un proceso de culminación de caída de los precios reales en el año 2000, con un escenario estable en la actualidad y sin recuperación de los precios por ahora.

Este fenómeno implicará que la agricultura vuelva a ser un eje estratégico para el desarrollo económico y social de los países en las próximas décadas. Con alimentos baratos la gente del campo migró a la gran ciudad, al igual que los jóvenes, como consecuencia del problema de recambio generacional. Pero ahora el proceso es casi seguro que se revertirá con movilización de personas hacia las ciudades cercanas al sector productivo, e incluso cambiará la disponibilidad del salario para consumos que no sean alimentos y esto repercutirá en otros sectores.

En este contexto, las preguntas clave son: $¿ \mathrm{Se}$ verifican cambios en los mercados agrarios en los próximos años, además de la recuperación de los precios reales en algunos sectores? ¿Y en particular en el comercio del espárrago como producto no tradicional en América Latina?

La respuesta a esta última pregunta es el objetivo de este artículo, donde se analiza particularmente el modelo del Perú y su proceso de adaptación al cambio, dado que es el principal exportador mundial del espárrago.

En la sección II se aborda el comercio mundial del espárrago, sus exportaciones e importaciones. En la sección III se presenta el mapa de competitividad sobre la base del Índice de competitividad de comercio exterior (ICCE). La sección IV se refiere a la evolución sectorial en lo que atañe a la producción, el tipo de cambio, la estructura comercial y la política empresarial. Finalmente, en la sección $\mathrm{V}$ se entregan las principales conclusiones. 


\section{II}

\section{Comercio mundial del espárrago}

\section{Exportaciones}

La exportación de espárragos en fresco reporta anualmente un ingreso de 1.027 millones de dólares, con un volumen de 343.000 toneladas. El crecimiento anual promedio en el período 2003-2012 fue de un 7,7\% en la facturación en dólares, mientras que el volumen creció a un 5\% anual en promedio, lo que explica que el precio $\mathrm{FOB}^{1}$ de exportación solo registrara un incremento de un $2,3 \%$ anual en el período analizado. Perú es el principal exportador mundial, contabilizando un incremento de un $6,7 \%$ anual en su volumen de venta externa y de un $11 \%$ anual en su facturación.

Al año 2000, la participación por exportación a nivel mundial es la siguiente: Perú: 33,1\%; México: 22,3\%; Estados Unidos de América: 15\%; Holanda: 8,4\%; España: 4,5\%; Alemania: 2,1\%; Italia: 2,1\%; Grecia: 2\%; Francia: 2\%; Australia: 1,7\%; Tailandia: $1,2 \%$; Polonia: $0,9 \%$, y Hungría: $0,9 \%$ (véase el cuadro 1 ).

El 60\% de la exportación mundial de espárragos en 2012 se realizó en el período de enero a junio, mientras que el $40 \%$ restante correspondió a los meses de julio a diciembre. Cuando un país efectúa exportaciones fuera de su calendario de producción, generalmente

\footnotetext{
1 Precio franco a bordo.
}

está comercializando espárragos de otros países que importó previamente.

A nivel de países se pueden hacer las siguientes diferenciaciones en cuanto a la estacionalidad de la producción, las que explican la oferta exportable mundial: i) el Perú y Tailandia son los únicos países que producen todo el año; ii) los Estados Unidos de América producen de enero a septiembre; iii) España lo hace de enero a julio, mientras que Francia y Portugal, de marzo a julio; iv) Alemania y Holanda producen de agosto a noviembre; v) China, en dos períodos: de febrero a julio y de septiembre a diciembre; vi) el Canadá lo hace en los meses de mayo y junio; vii) México produce en dos períodos: de enero a abril y de junio a octubre; viii) el Ecuador, de junio a febrero; ix) Chile, de julio a diciembre; $x$ ) Nueva Zelanda, de septiembre a diciembre y xi) Australia, de septiembre a noviembre.

\section{Importaciones}

La importación de espárragos en fresco implica un desembolso anual de 1.200 millones de dólares por parte de los países compradores, con un volumen de 343.000 toneladas.

Tomando en consideración la tasa anual sobre la base de los datos del cuadro 2, con la metodología de cálculo de la pendiente de la tendencia de ajuste lineal,

CUADRO 1

Facturación mundial de exportación de espárragos en fresco, 2003-2012

(En miles de dólares)

\begin{tabular}{|c|c|c|c|c|c|c|c|c|c|c|}
\hline Países & 2003 & 2004 & 2005 & 2006 & 2007 & 2008 & 2009 & 2010 & 2011 & 2012 \\
\hline Total & 497848 & 550831 & 602971 & 663382 & 709361 & 738116 & 761765 & 902963 & 955879 & 1026809 \\
\hline Perú & 108343 & 141545 & 160015 & 187364 & 235701 & 230427 & 250823 & 290684 & 291828 & 339987 \\
\hline México & 77357 & 78508 & 114044 & 129094 & 116553 & 101582 & 146209 & 217413 & 229822 & 228767 \\
\hline Estados Unidos & 69137 & 70527 & 81075 & 79611 & 81719 & 95178 & 101241 & 128861 & 140148 & 153955 \\
\hline Holanda & 28186 & 35627 & 32148 & 38325 & 53338 & 65113 & 59867 & 56014 & 70807 & 86343 \\
\hline España & 77869 & 70908 & 59130 & 64391 & 51677 & 51731 & 47109 & 40771 & 47146 & 46508 \\
\hline Grecia & 29861 & 33029 & 31273 & 38932 & 43665 & 50289 & 32793 & 39051 & 22835 & 20260 \\
\hline Tailandia & 15625 & 24532 & 28093 & 26266 & 23601 & 23406 & 17540 & 12974 & 15618 & 12042 \\
\hline Alemania & 4590 & 5126 & 7274 & 8825 & 9482 & 11958 & 10934 & 16698 & 21409 & 21954 \\
\hline Italia & 2315 & 2829 & 4072 & 4569 & 7788 & 12778 & 9902 & 13949 & 16192 & 21787 \\
\hline Francia & 27517 & 22829 & 20037 & 22843 & 19012 & 17548 & 19630 & 16477 & 20639 & 20470 \\
\hline Australia & 14579 & 19661 & 16969 & 13562 & 13802 & 20538 & 11887 & 15822 & 16842 & 17029 \\
\hline Polonia & 3076 & 4087 & 3396 & 3521 & 2906 & 3716 & 5567 & 7027 & 9145 & 9389 \\
\hline Hungría & 5392 & 6355 & 5366 & 5854 & 7390 & 11797 & 10391 & 9971 & 7847 & 9678 \\
\hline Otros países & 34001 & 35268 & 40079 & 40225 & 42727 & 42055 & 37872 & 37251 & 45601 & 38640 \\
\hline
\end{tabular}

Fuente: elaboración propia mediante datos del Centro de Comercio Internacional (CCI) y de la Base de datos estadísticos sobre el comercio de mercaderías (COMTRADE). 


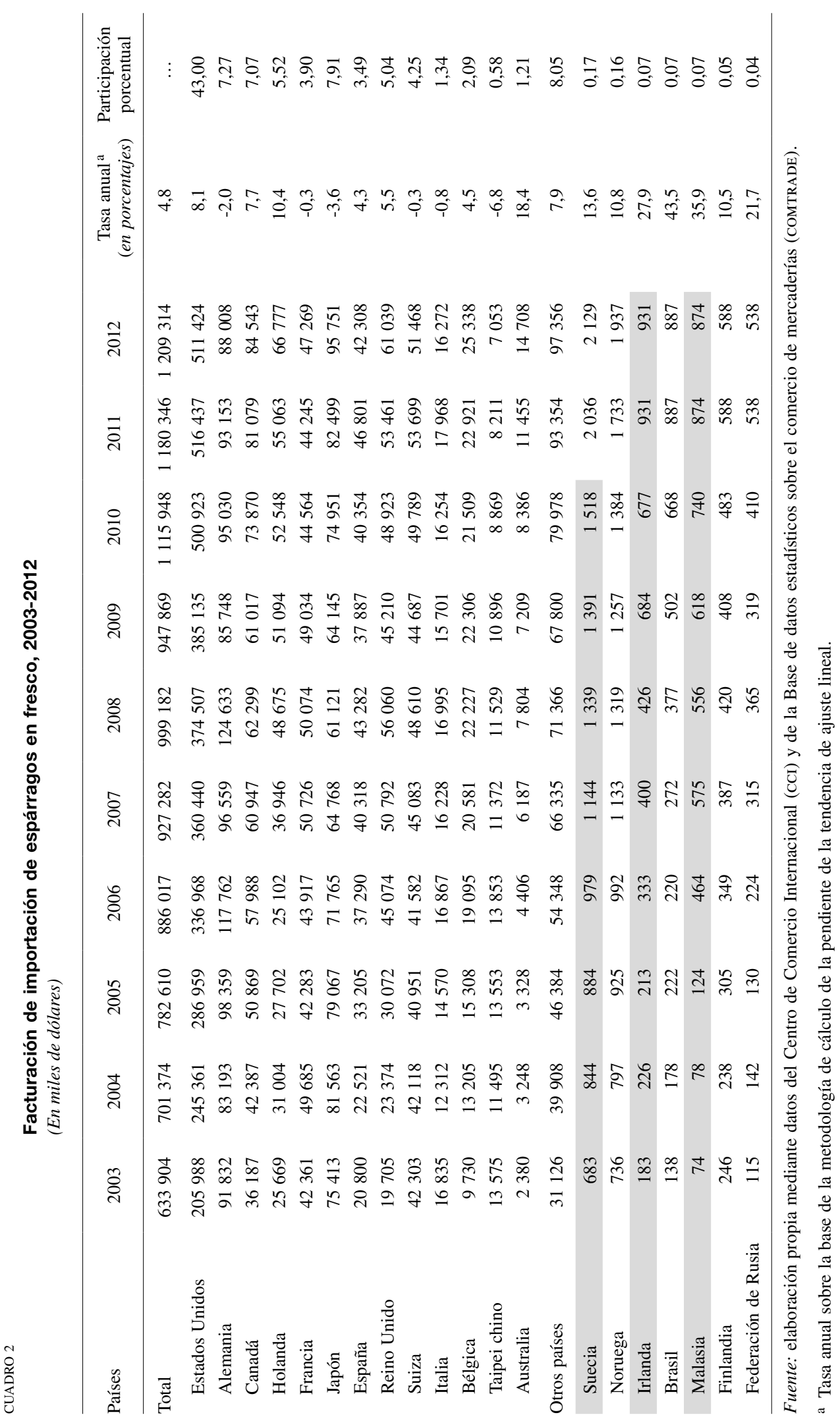


el comercio mundial crece a un ritmo del $4,8 \%$ anual (de 2003 a 2012), y los países compradores con tasas de crecimiento superiores al promedio mundial son: Brasil (43,5\%); Malasia (35,9\%); Irlanda (27,9\%); Federación de Rusia (21,7\%); Australia (18,4\%); Suecia (13,6\%); Noruega (10,8\%); Finlandia (10,5\%); Holanda (10,4\%); Canadá $(7,7 \%)$, y el Reino Unido e Irlanda del Norte
$(5,5 \%)$. Por otra parte, países relevantes que retroceden en su tendencia de compra son Italia, Alemania y el Japón. La participación de los compradores más relevante es la siguiente: Estados Unidos de América 42,3\%; Japón 7,9\%; Alemania 7,3\%; Canadá 7\%; Holanda 5,5\%; el Reino Unido $5 \%$; Suiza 4,3\%; Francia 3,9\%; España 3,5\%; Bélgica 2,1\%; Italia 1,3\%; Australia 1,2\%, y Taipei Chino 0,6\%.

\section{III}

\section{Mapa de competitividad}

\section{1. Índice de competitividad de comercio exterior (ICCE)}

Por ahora, solo es unánime el concepto economicista de competitividad desarrollado por el Foro Económico Mundial y utilizado para elaborar el índice mundial de competitividad a nivel de países. Este índice mide un conjunto de instituciones, políticas y factores que definen los niveles de prosperidad económica sostenible hoy en día y a mediano plazo. En cuanto a definiciones sobre competitividad sectorial o empresarial, es amplio el abanico; sin embargo, el concepto más apropiado para el comercio internacional desde el punto de vista de este estudio es el de "la capacidad de mantener o expandir su participación en los mercados y, además, elevar simultáneamente el nivel de vida de la población vinculada a la zona de producción". Sobre la base de esta definición, una herramienta adecuada es el índice de competitividad de comercio exterior (ICCE), que relaciona como numerador la "cuota de mercado" en los países importadores relevantes de un producto en particular, y como denominador la "participación" del país en la exportación mundial del mismo producto:

Fórmula: $\operatorname{ICCE}=\left(M_{k i j} / M_{k j}\right) /\left(X_{k i} / X_{k w}\right)$

donde:

$\mathrm{M}_{k i j} \quad$ Importación del producto " $\mathrm{k}$ ” del país "i” en el país "j"

$\mathbf{M}_{k j} \quad$ Importación total del producto "k" en el país “j”

$\mathrm{X}_{k i} \quad$ Exportación de " $\mathrm{k}$ " por el país "i"

$\mathrm{X}_{k w}$ Exportación mundial (w) del producto "k"

Los datos provienen de la facturación en valores monetarios y no en volumen, considerando que esta es más relevante como indicador de competitividad porque incorpora en el estudio el valor agregado del producto analizado. En la medida en que la cuota de participación en un mercado internacional fuese superior a la participación mundial como exportador, ello denotaría mayor competitividad porque la cuota de mercado superaría a la participación mundial, y viceversa si fuera inferior.

Combinar en un análisis el ICCE y la tendencia de la cuota de mercado - porque es una variable efecto y no causa - resulta un método efectivo para obtener en un país "un mapa de la competitividad mundial" de un producto, y además facilitar la visualización de la tendencia en los mercados relevantes bajo el paradigma de la complejidad y la adaptabilidad comercial. Esto implica un mayor número de países importadores, con la particularidad de cambios continuos en la competencia entre proveedores internacionales debido a la variación en la cuota de mercado, originada en la variación de la política comercial -precio, volumen o ambos- de alguno de ellos.

En la construcción del "mapa de competitividad", se considera en el eje horizontal la cuota de mercado en los principales países importadores en relación con la media de participación mundial del país de origen en el producto analizado, mientras que en el eje vertical se compara la tendencia de la cuota de mercado en un determinado período, teniendo en cuenta que el tamaño del círculo que representa la facturación anual en dólares indica su relevancia (véase el gráfico 1).

Esta metodología también es eficiente porque no resulta costoso el acceso a datos de comercio internacional, y es efectiva porque cumple con el objetivo para el que se creó. Se utilizó para analizar frutas como kiwifruit (De Pablo y Giacinti, 2012a); pera (De Pablo, Giacinti, 2012b; De Pablo, Giacinti y Uribe, 2012); manzana (De Pablo y Giacinti, 2012c), y limón (De Pablo, Giacinti, 2013). 
GRÁFICO 1

Perú: mapa de competitividad en exportación del espárrago, 2003-2011

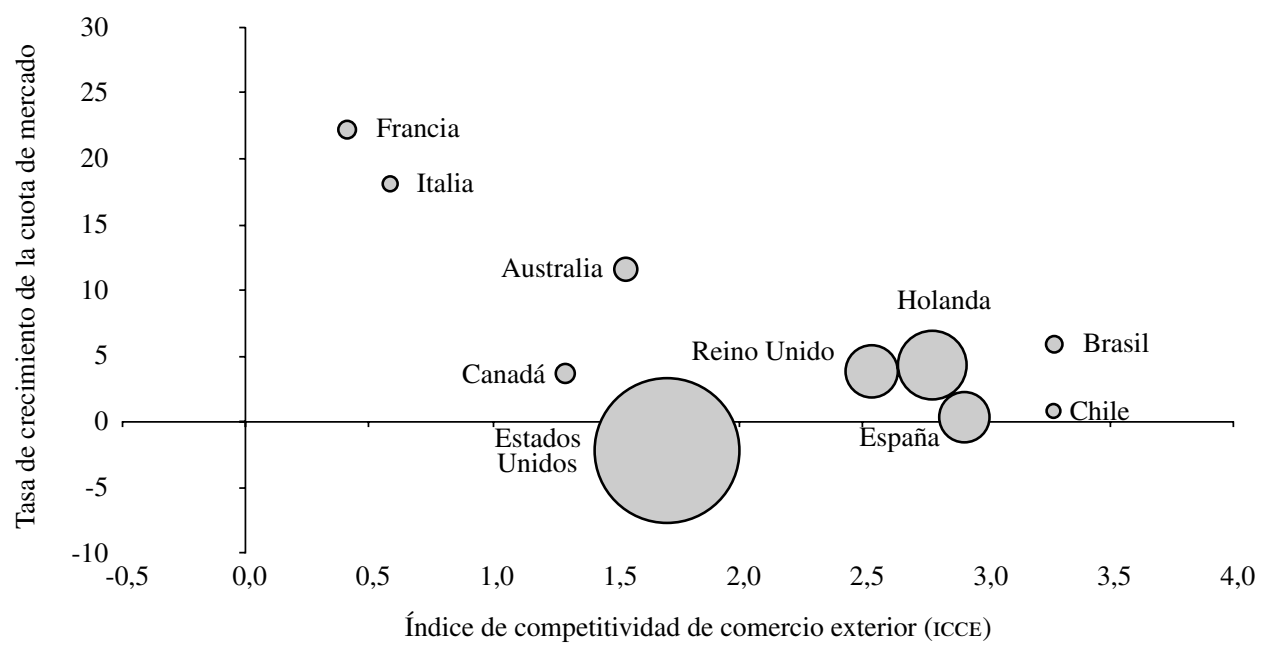

Fuente: elaboración propia sobre la base de datos del cuadro 3.

Nota: tamaño del círculo indica el valor de exportación en 2011.

\section{Resultado}

Perú tiende a diversificar su comercio internacional del espárrago (véase el gráfico 1), pero su principal cliente continúa siendo el mercado de los Estados Unidos de América con el 60,58\% de sus ventas, las que ingresan con $0 \%$ de arancel. También tienen importancia las ventas a Holanda $(13,62 \%)$; el Reino Unido $(7,89 \%)$ y España (7,32\%).

En el cuadro 3 se observa cómo en la actualidad los mayores valores del índice de competitividad de comercio exterior (ICCE) están en el Brasil $(3,28)$; España (2,91); Holanda (2,78), y el Reino Unido (2,54); mientras que los Estados Unidos de América tienen un valor de 1,70. También se observa que solo los Estados Unidos de América presentan valores negativos en la tasa anual de variación de la cuota de mercado $(-2,2 \%)$, mientras que los mayores valores los tienen el Japón $(34,5 \%)$; Francia (22,3\%); Italia (18,1\%), y Australia (11,6\%). Incluso la cuota de mercado de algunos países supera a la existente en los Estados Unidos de América - con fuerte competencia de México-, como es el caso del Reino Unido, Holanda, España, Chile y el Brasil.

Los cambios observados en los países importadores de espárragos peruanos validan el nuevo paradigma de la competitividad dinámica, ya que esta no es global y presenta particularidades en su tasa de crecimiento en cada mercado.
CUADRO 3

Perú: indicadores del comercio del espárrago, 2011

\begin{tabular}{lccr}
\hline Importador & ICCE & $\begin{array}{c}\text { Cuota de mercado. } \\
\text { Variación anual } \\
\text { (en porcentajes) }\end{array}$ & $\begin{array}{c}\text { Exportaciones } \\
\text { (en millones de } \\
\text { dólares })\end{array}$ \\
\hline Estados Unidos & 1,70 & $-2,2$ & 176790 \\
Holanda & 2,78 & 4,4 & 39749 \\
Reino Unido & 2,54 & 3,9 & 23037 \\
España & 2,91 & 0,4 & 21348 \\
Japón & 0,49 & 34,5 & 4651 \\
Australia & 1,54 & 11,6 & 4471 \\
Canadá & 1,29 & 3,6 & 3046 \\
Francia & 0,41 & 22,3 & 2621 \\
Brasil & 3,28 & 6,0 & 2276 \\
Italia & 0,58 & 18,1 & 1878 \\
Chile & 3,27 & 0,8 & 1602 \\
\hline
\end{tabular}

Fuente: Centro de Información Frutihortícola (CIF), "Business Intelligence" [en línea] http://www.cif-businessintelligence.com/ observatorio_bi.html; y Base de datos estadísticos sobre el comercio de mercaderías (COMTRADE).

ICCE: índice de competitividad de comercio exterior.

Resulta llamativo ver que Alemania (véase el cuadro 2), el país con mayor consumo per cápita y segundo importador del mundo, no está entre los clientes del Perú de manera directa. La respuesta está dada por Holanda que, como en otras frutas y hortalizas, actúa como intermediario comercial (broker), y así realiza una triangulación comercial con mercados 
europeos cuyo costo de comercialización es mayor. Si bien el Japón y los Estados Unidos de América son los otros grandes consumidores de espárragos a nivel mundial, este último país es el principal cliente del Perú, mientras que el Japón es marginal por ahora, pero en los años de estudio del presente trabajo se observa que sus compras se han incrementado de manera muy significativa. Estas observaciones también permiten avizorar que el paradigma de la gestión no está desarrollado en toda su dimensión en el negocio del comercio del espárrago peruano, adaptándose al pleno potencial de mercado existente.

\section{IV}

\section{Evolución sectorial}

\section{Producción}

Las principales zonas de producción en el Perú se ubican en la costa, en los departamentos de La Libertad, Ica y Lima.

En la costa norte se siembran los espárragos blancos, especialmente en los alrededores de Trujillo, y los verdes se cultivan entre Lima y la ciudad sureña de Arequipa. Según datos oficiales, el crecimiento anual promedio de la superficie cultivada de espárragos en el Perú es de un 8,9\% en el período 2004-2011, contabilizando algo más de 30.000 hectáreas en 2011. El incremento de la oferta exportable de 2004 a 2011 obedece al aumento de la superficie cultivada — 18.900 a 30.000 has. con mejora tecnológica- y a una etapa inicial con buenos precios internacionales (Illescas y Jaramillo, 2011), generando 120.000 empleos directos e indirectos en el campo, según fue manifestado en el V Congreso Internacional del Espárrago realizado en el 2010 en el Perú2.

En el período 2004-2012 (véase el cuadro 4), la exportación total de espárragos peruanos se acrecentó a una tasa media anual de un 5,6\% en lo que se refiere

2 http://www.exportando-peru.com/tips-detalle.php?idnoticia=603 \&idcategoria $=9$. al volumen, con una tasa de un 3,2\% anual en el caso del espárrago en conservas y una tasa de un $6,9 \%$ en cuanto al espárrago en fresco o refrigerado. También se verificó una caída en la producción de espárragos que repercutió en un menor despacho en el comercio exterior en 2012, debido a factores climáticos y a la realidad agronómica del sector de plantaciones antiguas, que son erradicadas, pero migran a otros cultivos ante dificultades de rentabilidad en el sector del espárrago ocasionadas por el aumento de los costos internos en dólares.

Perú es el principal exportador mundial en fresco o refrigerado, pero conviene acotar que es el segundo en conserva, aunque en 2012 superó levemente a China en volumen y fue el líder mundial. La exportación de conservas de espárragos se ha expandido desde finales de la década de 1980, aunque hubo cierto estancamiento a mediados del decenio de 1990. Los espárragos frescos y en conserva constituyen el segundo producto agrícola de exportación en el Perú después del café.

Si se tiene en cuenta la facturación anual en dólares, el Perú siempre se ha posicionado como el principal comercializador mundial de espárragos en conserva desde el año 2004. El principal destino comercial de este producto son países europeos (véase el cuadro 5), mientras que en fresco el principal mercado son los Estados Unidos de América (véase el cuadro 6).

CUADRO 4

Perú: exportación total de espárragos, 2004-2012

(En toneladas)

\begin{tabular}{lrrrrrrrrrr}
\hline Detalle & 2004 & 2005 & 2006 & 2007 & 2008 & 2009 & 2010 & 2011 & $\begin{array}{r}2012 \\
(\text { en porcentajes) }\end{array}$ \\
\hline Total exportado & 112247 & 121007 & 137857 & 154222 & 167422 & 163928 & 173945 & 197074 & 173497 & 5,6 \\
$\quad$ En conserva & 40184 & 41353 & 45448 & 58598 & 63563 & 49837 & 47070 & 60757 & 53816 & 3,2 \\
$\quad$ En fresco & 72063 & 79654 & 92409 & 95624 & 103859 & 114091 & 126875 & 136317 & 119681 & 6,9
\end{tabular}

Fuente: elaboración propia sobre la base de datos de la Superintendencia Nacional de Aduanas y de Administración Tributaria (suNAT) del Perú.

a Tasa anual sobre la base de la metodología de cálculo de la pendiente de la tendencia de ajuste lineal. 
CUADRO 5

Perú: exportación de espárragos en conserva, 2004-2012

(En toneladas)

\begin{tabular}{lrrrrrrrrr}
\hline Mercados & 2004 & \multicolumn{2}{c}{2005} & 2006 & 2007 & 2008 & 2009 & 2010 & 2011 \\
\hline África & 0 & 0 & 0 & 0 & 0 & 308 & 50 & 0 & 113 \\
Asia & 1636 & 1491 & 1133 & 1019 & 1339 & 1306 & 1433 & 1458 & 1688 \\
Europa & 32989 & 29962 & 31126 & 44405 & 43117 & 35116 & 35166 & 45269 & 37114 \\
América Latina & 421 & 440 & 822 & 912 & 921 & 849 & 966 & 1223 & 1446 \\
MERCosur & 0 & 9 & 0 & 11 & 11 & 2 & 0 & 2 & 11 \\
América del Norte & 5137 & 9451 & 12366 & 12252 & 18176 & 12255 & 9456 & 12805 & 13445 \\
Federación de Rusia & 0 & 0 & 0 & 0 & 0 & 0 & 0 & 0 & 0 \\
Total general & 40 & 41353 & 45448 & 58598 & 63563 & 49837 & 47070 & 60757 & 53816 \\
\hline
\end{tabular}

Fuente: elaboración propia sobre la base de datos de la Superintendencia Nacional de Aduanas y de Administración Tributaria (sunAT) del Perú.

CUADRO 6

Perú: exportación de espárragos en fresco o refrigerados, 2004-2012 (En toneladas)

\begin{tabular}{|c|c|c|c|c|c|c|c|c|c|}
\hline Mercados & 2004 & 2005 & 2006 & 2007 & 2008 & 2009 & 2010 & 2011 & 2012 \\
\hline África & 0 & 45 & 96 & 106 & 81 & 66 & 105 & 146 & 133 \\
\hline Asia & 624 & 1017 & 1662 & 1558 & 1400 & 2174 & 3167 & 3294 & 3553 \\
\hline Europa & 15277 & 18692 & 21485 & 22342 & 25745 & 28499 & 32098 & 33738 & 33310 \\
\hline América Latina & 191 & 265 & 465 & 458 & 341 & 528 & 723 & 1083 & 855 \\
\hline Oriente Medio & 11 & 3 & 7 & 8 & 2 & 7 & 13 & 44 & 57 \\
\hline MERCOSUR & 164 & 244 & 400 & 571 & 741 & 902 & 1216 & 1528 & 1915 \\
\hline América del Norte & 55796 & 59373 & 68283 & 70582 & 75544 & 81915 & 89549 & 96485 & 79855 \\
\hline Federación de Rusia & 0 & 15 & 11 & 0 & 6 & 0 & 3 & 0 & 2 \\
\hline Total general & 72063 & 79654 & 92409 & 95624 & 103859 & 114091 & 126875 & 136317 & 119681 \\
\hline
\end{tabular}

Fuente: elaboración propia sobre la base de datos de la Superintendencia Nacional de Aduanas y de Administración Tributaria (sunAT) del Perú.

A pesar de tener una oferta durante todos los meses del año, la actividad productiva y comercial tiene como principal ventana los meses de julio a diciembre (Benson, 2012), con el $68 \%$ en los últimos años. El $85 \%$ de las exportaciones en fresco o refrigerado se despacharon por vía aérea, mientras que la media del período $2004-2012$ es del $80 \%$, con extremos del $70 \%$ y el $91 \%$ en el mismo lapso.

En este proceso de crecimiento tuvo gran influencia el cambio de política, como es el caso de una legislación que no determinaba límites para el tamaño de la propiedad agrícola; establecía los mismos derechos y obligaciones para los capitales nacionales y extranjeros; promovía el desarrollo mediante una reducción del impuesto del 15\% a las utilidades de las sociedades; y otorgaba incentivos regionales de exención de impuestos durante 15 años a inversores de activos en zonas especiales destinadas a la exportación e infraestructura básica para riego de cultivos, por ejemplo, el proyecto Chavimochic en el Departamento de la Libertad. La creación del Ministerio de Comercio Exterior y Turismo también constituye un pilar en la política pública, no solo porque impulsa acuerdos comerciales con otros países, sino también por la implementación de la Comisión de Promoción del Perú para la Exportación y el Turismo (PromPerú), el Plan Estratégico Nacional Exportador (PENX) y la Ventanilla Única de Comercio Exterior (VUCE).

\section{Tipo de cambio}

Un factor macroeconómico que afecta a la rentabilidad del cultivo y la exportación del espárrago peruano es la paridad de su moneda frente al dólar estadounidense. En el Departamento de Agricultura de los Estados Unidos de América, a través del Servicio de Investigación Económica (ERS por sus siglas en inglés), se elaboran estadísticas de la evolución de la paridad de las monedas en muchos países, analizando su evolución nominal y real. En el gráfico 2 se observa cómo el Nuevo Sol se fortalece y con ello aumentan los costos en dólares, mientras que en México su moneda tendió, hasta 2012, a debilitarse y a disminuir el costo interno en dólares por efecto de 
GRÁFICO 2

Paridad real frente al dólar de las monedas de México y el Perú, 2004-2013

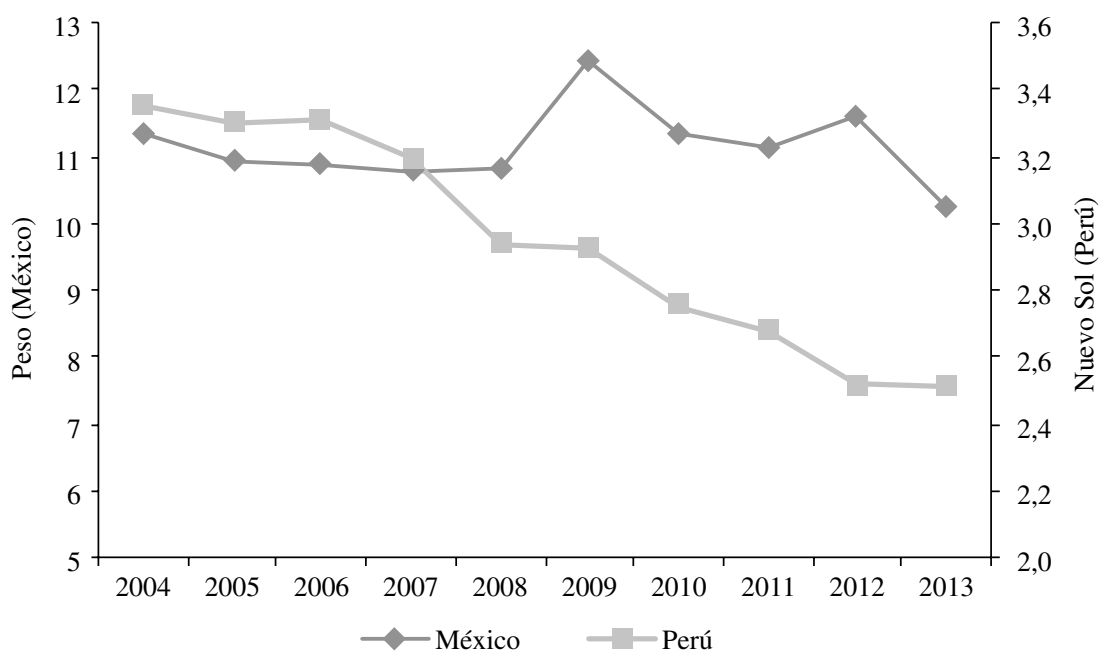

Fuente: Departamento de Agricultura de los Estados Unidos de América, "Mathew Shane" [online] http://www.ers.usda.gov/ers-staffdirectory/mathew-shane.aspx\#.UsLYY9JDuSo.

la paridad cambiaria. Esto exige mayor incorporación tecnológica en toda la cadena del espárrago peruano -incluso en la logística y comercialización, además de la producción y el empaque-, y optimizar su gestión para mejorar el desempeño económico del sector.

\section{Estructura comercial}

\section{a) Índice de Herfindahl-Hirschman (IHH)}

Para analizar los cambios en la estructura del comercio mundial, que van más allá de la evolución de los precios reales, se utiliza el IнH, que es la única herramienta de sustento legal en la Unión Europea, los Estados Unidos de América $^{3}$ y otros países, como lo señalan algunas investigaciones (Sawaya Jank, Paes Leme y Meloni Nassar, 2001; Mariscal y Rivera, 2007; Durán Lima y Álvarez, 2008; Baumann, 2009; Alarco y del Hierro, 2010; Petit, 2012; Caputi Lélis, Moreira Cunha y Gomes de Lima, 2012; Fadzlan y Muzafar, 2013). También hay quienes analizan si el IHн es efectivo o si requiere ajustes (Hirschman, 1964; Djolov, 2011).

Este índice mide la concentración de mercado, dado que tiene en cuenta tanto el número de competidores como su participación relativa en este, y se calcula como la suma al cuadrado de la participación porcentual de la i-ésima empresa en la industria. En la siguiente fórmula se expresa su cálculo:

\footnotetext{
${ }^{3}$ http://www.justice.gov/atr/public/testimony/hhi.htm.
}

$$
\mathrm{IHH}=\sum_{\mathrm{i}=1}^{\mathrm{n}}\left(\frac{X_{i}}{X} 100\right)^{2}
$$

donde:

$\frac{X_{i}}{X}$ participación de la i-ésima empresa en el mercado

(n) número de empresas en la industria

La escala utilizada en los Estados Unidos de América es la siguiente: i) $\mathrm{IHH}<1.000=$ nivel bajo de concentración; ii) $1.000<\mathrm{IHH}<1.800=$ nivel moderado de concentración, y iii) IHH $>1.800=$ nivel alto de concentración.

La normativa de la Unión Europea solo difiere en que es necesario superar los 2.000 puntos para estar en presencia de alta concentración económica.

Para poder comparar datos entre países o bien analizar alguna explicación sobre la evolución del IHH en una serie de tiempo, resulta válido normalizar los datos para eliminar el efecto agregación del número de empresas (Baumann, 2009). Esto implica un nuevo índice en términos porcentuales, solo para los efectos de comparación o análisis, con la siguiente fórmula en el presente caso:

$$
\frac{\sqrt{H H I}-\left(100 * \sqrt{\frac{1}{n}}\right)}{100 *\left(1-\sqrt{\frac{1}{n}}\right)}
$$




\section{b) Concentración de mercado}

La estructura del modelo peruano de exportación del espárrago en fresco es de baja concentración (por debajo de los 1.000 puntos en la escala del IHH), con una tendencia creciente a menores niveles por medio de una tasa de disminución anual de un 4,3\% en el período 2002-2012 (véase el cuadro 7).

Los mercados con mayor volumen comercial, como es el caso de las ventas a América del Norte y Europa, son de baja concentración, mientras que otros mercados de menor relevancia son por ahora de moderada concentración (América Latina, MERcosur y Asia) y alta concentración (África y Oriente Medio).

Los registros de importadores por vía marítima, analizados a través del IHH, proyectan una estructura de baja concentración comercial (véase el cuadro 8), con la salvedad de que en 2012 se redujo la exportación por este medio debido a la menor cosecha, lo que explica el aumento del índice en relación al año 2011. El mayor volumen de exportación del espárrago es por vía aérea, pero los registros no estaban disponibles a través de ese medio de transporte, a diferencia del caso marítimo. En este último caso, los datos indican un mercado de baja concentración en América del Norte — principal destino del espárrago peruano-, a diferencia del mercado de América Latina de moderada concentración, mientras que resultan de alta concentración los de Europa y Asia.

El aumento de las empresas exportadoras de 60 en 2002 a 99 en 2012 (véase el cuadro 9); es uno de los elementos que explican la menor concentración económica del sector en general, además de la cuota de mercado de las principales exportadoras. Algunas empresas han iniciado un proceso de diversificación de ventas, y cultivan y exportan menos espárragos, pero aumentan su oferta de otros productos, por ejemplo: palta, uva de mesa o arándanos para el mercado de Europa, América Latina, Asia y América del Norte. La variación de su participación en la cuota de mercado en grandes empresas, más el incremento de exportadoras, explican la menor concentración económica. Por otra parte, en el caso del MERCosur y del Oriente Medio no hay diversificación de ventas o menor volumen de exportación de las empresas más importantes, como son: Complejo Agroindustria Beta, Damper Trujillo, Agrícola la Venta o Agro Paracas, sino que tan solo el crecimiento de nuevos exportadores explica la menor concentración económica; por esta razón el IHH normalizado es positivo (véase el cuadro 10), mientras que en los mercados el

CUADRO 7

Perú: índice de Herfindahl-Hirschman en la exportación de espárragos en fresco, 2002-2012

\begin{tabular}{|c|c|c|c|c|c|c|c|c|c|c|c|c|}
\hline Mercados & 2002 & 2003 & 2004 & 2005 & 2006 & 2007 & 2008 & 2009 & 2010 & 2011 & 2012 & $\begin{array}{c}\text { Crecimiento } \\
\text { anual } \\
\text { (en porcentajes) }\end{array}$ \\
\hline \multicolumn{13}{|l|}{ IHH exportación } \\
\hline Promedio & 687 & 563 & 488 & 476 & 463 & 427 & 380 & 384 & 380 & 419 & 420 & $-4,3$ \\
\hline América del Norte & 751 & 599 & 391 & 315 & 293 & 300 & 297 & 332 & 369 & 410 & 347 & $-5,5$ \\
\hline Europa & 1209 & 1350 & 1139 & 1247 & 1133 & 1032 & 753 & 742 & 714 & 731 & 860 & $-5,5$ \\
\hline América Latina & 4266 & 3207 & 4087 & 4786 & 5489 & 3542 & 3869 & 2779 & 2326 & 2635 & 1715 & $-5,8$ \\
\hline MERCOSUR & 4374 & 3025 & 1677 & 2676 & 5231 & 4768 & 1513 & 1450 & 1172 & 1557 & 1364 & $-8,7$ \\
\hline Asia & 10000 & 7279 & 9019 & 6712 & 4707 & 5047 & 2386 & 1465 & 1437 & 1556 & 1707 & $-19,7$ \\
\hline África & & & & 8238 & 9319 & 9711 & 9399 & 4087 & 5680 & 9057 & 8361 & $-2,3$ \\
\hline Oriente Medio & & & & 5159 & 10000 & 9949 & 10000 & 6172 & 3987 & 4546 & 3101 & $-10,0$ \\
\hline
\end{tabular}

Fuente: elaboración propia sobre la base de datos de la Superintendencia Nacional de Aduanas y de Administración Tributaria (suNAT) del Perú.

CUADRO 8

Perú: índice de Herfindahl-Hirschman en la importación de espárragos en fresco por vía marítima, 2011-2012

\begin{tabular}{lr}
\hline Mercados & 2011 \\
\hline IHH importación & 2012 \\
Promedio & 489 \\
América del Norte & 816 \\
Europa & 962 \\
América Latina & 1510 \\
Asia & 2304 \\
\hline
\end{tabular}

Fuente: elaboración propia sobre la base de datos de Fresh Cargo [en línea] http://www.qcfreshfruit.com/. 
Perú: número de empresas exportadoras de espárragos en fresco por regiones comerciales, 2002-2012

\begin{tabular}{|c|c|c|c|c|c|c|c|c|c|c|c|c|}
\hline Mercados & 2002 & 2003 & 2004 & 2005 & 2006 & 2007 & 2008 & 2009 & 2010 & 2011 & 2012 & $\begin{array}{c}\text { Crecimiento } \\
\text { anual } \\
\text { (en porcentajes) }\end{array}$ \\
\hline América del Norte & 59 & 61 & 86 & 103 & 110 & 101 & 98 & 102 & 86 & 82 & 83 & 1,8 \\
\hline Europa & 29 & 42 & 53 & 69 & 64 & 74 & 65 & 68 & 69 & 67 & 54 & 3,9 \\
\hline América Latina & 7 & 8 & 9 & 7 & 14 & 18 & 17 & 26 & 20 & 22 & 28 & 16,5 \\
\hline Asia & 1 & 3 & 9 & 16 & 13 & 21 & 27 & 32 & 27 & 30 & 27 & 24,9 \\
\hline África & & & & 5 & 6 & 3 & 2 & 5 & 4 & 4 & 3 & $-4,6$ \\
\hline Oriente Medio & & & & 2 & 1 & 2 & 1 & 5 & 3 & 6 & 8 & 41,2 \\
\hline
\end{tabular}

Fuente: elaboración propia sobre la base de datos de la Superintendencia Nacional de Aduanas y de Administración Tributaria (sunAT) del Perú.

CUADRO 10

Perú: índice de Herfindahl-Hirschman normalizado para la exportación de espárragos en fresco, 2002-2012

(En porcentajes)

\begin{tabular}{|c|c|c|c|c|c|c|c|c|c|c|c|c|}
\hline Mercados & 2002 & 2003 & 2004 & 2005 & 2006 & 2007 & 2008 & 2009 & 2010 & 2011 & 2012 & $\begin{array}{c}\text { Crecimiento } \\
\text { anual }\end{array}$ \\
\hline \multicolumn{13}{|l|}{ IHH normalizado } \\
\hline América del Norte & 14,9 & 12,2 & 9,5 & 8,4 & 8,1 & 7,8 & 7,6 & 8,8 & 8,9 & 9,7 & 8,1 & $-3,8$ \\
\hline Europa & 16,7 & 21,9 & 20,6 & 24,0 & 21,8 & 21,2 & 15,6 & 15,7 & 15,3 & 15,4 & 16,3 & $-2,9$ \\
\hline América Latina & 27,9 & 21,9 & 20,6 & 24,0 & 21,8 & 21,2 & 15,6 & 15,7 & 15,3 & 15,4 & 16,3 & $-5,0$ \\
\hline MERCOSUR & 8,5 & 22,1 & 13,5 & 24,5 & 31,9 & 41,9 & 11,5 & 16,1 & 13,8 & 20,4 & 17,8 & 0,1 \\
\hline Asia & 0,0 & 27,9 & 62,3 & 57,6 & 41,5 & 49,9 & 30,2 & 21,2 & 19,2 & 21,7 & 22,6 & $-3,1$ \\
\hline África & & & & 46,6 & 56,3 & 41,2 & 26,5 & 19,5 & 25,7 & 45,7 & 34,1 & $-5,4$ \\
\hline Oriente Medio & & & & 1,1 & 0,0 & 29,3 & 0,0 & 34,3 & 5,5 & 27,0 & 20,7 & 22,1 \\
\hline
\end{tabular}

Fuente: elaboración propia sobre la base de datos de la Superintendencia Nacional de Aduanas y de Administración Tributaria (sunAT) del Perú.

IHH normalizado es negativo porque además de crecer las exportadoras, las grandes empresas han disminuido su intensidad de ventas de espárragos para ofrecer otras frutas en su cartera comercial.

Las secuelas de la profundización en el deterioro de la paridad real de la moneda local a partir de 2010 (véase el grafico 2) son una disminución de empresas de 123 en 2009 a 99 en 2012 (véase el cuadro 9) y, en consecuencia, una leve propensión al aumento del IHH (en estos últimos años, véase el cuadro 7), aunque su posición se mantiene dentro del nivel de la escala de baja concentración económica.

La atomización de la estructura comercial del espárrago peruano debido a una menor concentración económica - más empresas y disminución de la cuota de mercado de los grandes comercializadores - vendría a ser un nuevo paradigma de la quinta revolución tecnológica. Este mismo fenómeno de concentración económica en la estructura de exportadores e importadores también se observa en el comercio exterior de Chile en el caso de sus frutas (tesis próxima a publicarse por la $\mathrm{ASOEX}^{4}$ como expediente 11), sobre todo y con mayor intensidad tiende a disminuir la concentración económica en uva de mesa, manzanas, frutas de carozo, arándanos, paltas y cítricos. En peras y kiwis la estructura es de baja concentración, pero estable o con leve tendencia a aumentar.

\section{Política empresarial}

a) Índice de politica de comercio exterior (IPCE)

El objetivo de esta metodología es analizar la política de venta empresarial, por ello el índice relaciona como numerador la "cuota de mercado en un país o región

\footnotetext{
${ }^{4}$ Asociación de Exportadores de Chile A.G.
} 
comercial" de una empresa y como denominador su "participación" en las ventas del país de ese producto:

$$
\operatorname{IPCE}=\left(V E_{k e j} / V E_{k e}\right) /\left(X_{k e} / X_{k i}\right)
$$

donde:

$\mathrm{VE}_{k e j}$ venta externa del producto "k" de la empresa "e" en el país "j"

$\mathrm{VE}_{k e}$ venta externa del producto " $\mathrm{k}$ " de la empresa "e"

$\mathrm{X}_{k e}$ exportación de " $\mathrm{k}$ " por la empresa "e"

$\mathrm{X}_{k i} \quad$ exportación de " $\mathrm{k}$ " desde el país "i"

Si para una empresa en particular la cuota de participación en un mercado es superior a la media de esta en la participación de la exportación del país con respecto al producto analizado, ello indicaría que existe una especialización de la firma en esa región. Una situación inversa daría entender que las ventas a esa región por ahora son marginales. La tendencia mostraría si la empresa presenta un aumento o no en el interés por vender en un país o región comercial en particular.

Esta herramienta fue desarrollada para entender el grado de adaptabilidad de las exportadoras a los cambios del comercio internacional bajo el paradigma de la complejidad (Spilzinger, 2004). Se relaciona con la teoría del "sistema complejo adaptativo" (Serlin, 2010), que se funda en la teoría de los sistemas dinámicos (en matemáticas) y en la teoría de los sistemas complejos (en gestión). Este enfoque es el que permite señalar la efectividad de la metodología — revalorizando la inteligencia comercial como medio para desarrollar la creatividad frente a un mundo complejo- a través de la adaptabilidad de la gestión de las ventas externas. Es eficaz porque cumple con su objetivo (análisis de la política de ventas) y efectivo cuando se tiene acceso a información detallada por empresas.

El análisis estadístico de disimilitud entre las empresas se hace sobre la base de la información de cada una de ellas respecto de tres elementos: la posición que presenta en el Índice de Política Comercial Exterior (IPCE), la tendencia de variación anual de este IPCE, y la facturación anual en dólares en cada región comercial (por ejemplo: Europa, Asia, África, América Latina, Oriente Medio, MERCOSUR y América del Norte). La combinación de estos tres elementos en cada empresa exportadora es lo que sustenta el análisis de disimilitud entre ellas.

La medida de disimilitud se obtiene a través del coeficiente de Gower (1967 y 1971), que tiene en cuenta el número de variables con datos para las comparaciones de a pares. A partir de la matriz obtenida se realiza un análisis multivariante de clúster jerárquico, considerando como criterio de encadenamiento el promedio de las distancias.

$$
S_{i j}=\frac{1}{p} \sum_{k=1}^{p} S_{i j k}
$$

En la situación más simple, cuando se comparan los individuos $i$ y $j$ para el carácter $k$, si este se trata de una variable binaria o cualitativa se asigna valor uno (1) a $S_{i j k}$ si $X_{i k}$ y $X_{j k}$ son iguales, y cero (0) si son diferentes. Si la variable es cuantitativa, la similitud entre los individuos estará dada por:

$$
\begin{gathered}
S_{i j k}=1-\frac{\left\|x_{l k}-x_{j k}\right\|}{r_{k h}}: S_{i j} \\
=\left(\sum_{k=1}^{p_{1}} \frac{\left\|x_{i k}-x_{j k}\right\|}{r_{k}}+a+d+\propto\right) /\left(p_{1}+p_{2}+p_{3}\right)
\end{gathered}
$$

donde:

$p_{1}$ número de variables cuantitativas

$r_{k}$ rango de la k-ésima variable continua

$p_{2}$ número de variables binarias

a número de coincidencias en 1 de las variables binarias

d número de coincidencias en 0 de las variables binarias $\left(p_{2}-d\right)$

$p_{3}$ número de variables cualitativas

$\alpha$ número de coincidencias de las variables cualitativas

\section{b) Plan de ventas}

El análisis estadístico mediante el coeficiente de Gower para elaborar una matriz de disimilitud, complementado con un análisis de clúster jerárquico de las empresas líderes (véase el gráfico 3), permite verificar la baja similitud en las políticas comerciales al comparar estas empresas. Ello resulta luego de confrontar la facturación por mercados, la posición del IPCE y su tasa de variación interanual (2004-2012) entre las principales exportadoras.

A modo de ejemplo, se pueden observar claramente asimetrías o diferencias en los mapas de competitividad de las exportadoras del Complejo Agroindustrial Beta (véase el gráfico 4) y Camposol (véase el gráfico 5). Además de estos dos casos, en general las principales empresas difieren entre ellas en la facturación económica de cada mercado y en la tasa de variación anual de posicionamiento o participación comercial. Esta evidencia valida el nuevo paradigma de mercados segmentados como proceso de adaptación comercial frente a los cambios, dado que cada empresa está viendo de manera diferente las oportunidades y amenazas de cada mercado. 
GRÁFICO 3

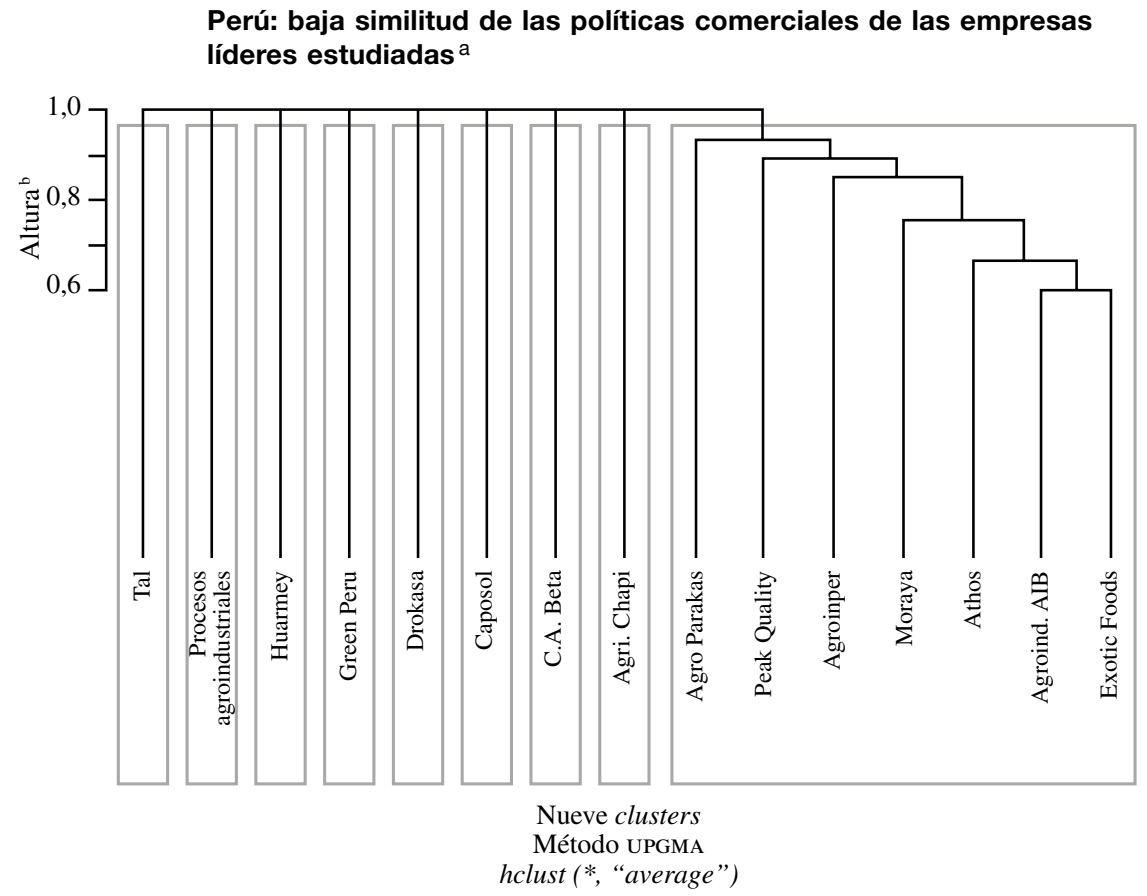

Fuente: elaboración propia sobre la base de datos de la Superintendencia Nacional de Aduanas y de Administración Tributaria (sunAT) del Perú.

a El gráfico fue construido mediante el programa estadístico R a partir de su función "hclust". En el eje vertical se indica la altura donde se agrupan los conglomerados. En el eje horizontal se señala el número de conglomerados (clusters) a partir del método UPGMA o "average".

b Respecto de la variable "altura", esta representa la distancia calculada a través del método UPGMA en la que se unen los distintos elementos y luego los distintos grupos conformados. Ello se expresa mediante los valores $0,6,0,8$ y 1,0 que son referencias relativas, siendo el valor 1,0 la distancia máxima de unión, en tanto que el valor 0,6 corresponde al 60\% de la distancia máxima. Estos valores permiten dar una idea visual de las magnitudes de las distancias en que se realizan los agrupamientos.

GRÁFICO 4

Complejo Agroindustrial Beta: tendencia en la política comercial, 2004-2012 (En porcentajes)

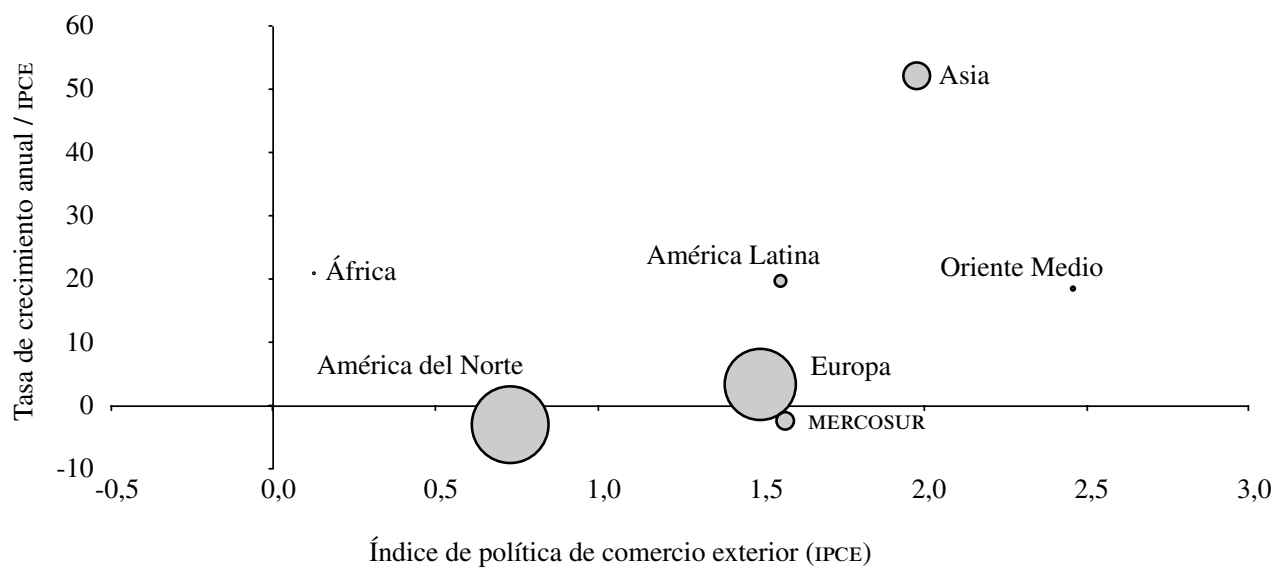

Fuente: elaboración propia sobre la base de datos de la Superintendencia Nacional de Aduanas y de Administración Tributaria (sunAT) del Perú.

Nota: tamaño del círculo indica la facturación de exportación en 2012. 
GRÁFICO 5

Camposol: tendencia en la política comercial, 2004-2012

(En porcentajes)

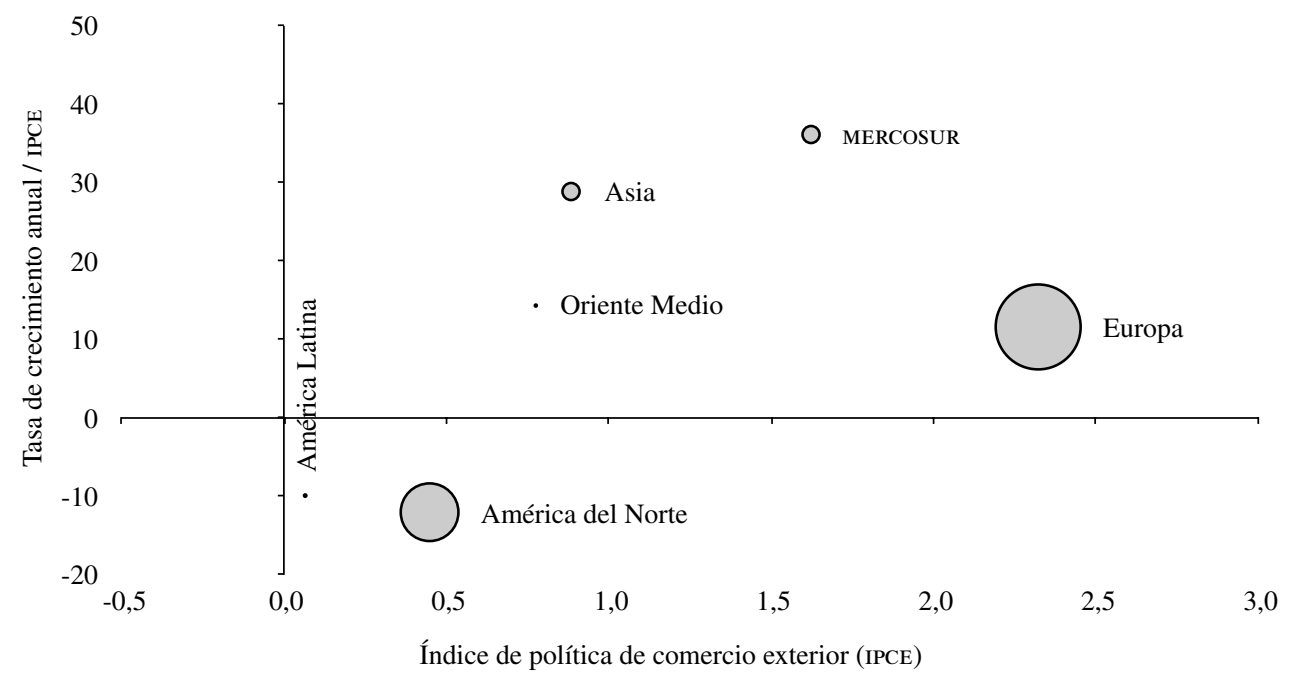

Fuente: elaboración propia sobre la base de datos de la Superintendencia Nacional de Aduanas y de Administración Tributaria (sunAT) del Perú.

Nota: tamaño del círculo indica la facturación de exportación en 2012.

\section{Posicionamiento de mercado}

\section{a) Matriz de competitividad en la importación} (TradeCAN)

El foco de análisis es ahora el mercado importador, con la meta de detectar los cambios que se verifican desde los proveedores internacionales pero, además, evidenciar las implicancias y el alcance del nuevo paradigma de la competitividad dinámica.

En el presente caso, se trata de entender la dinámica peruana y de los competidores en un país importador relevante (gráfico 1: Estados Unidos de América, Holanda, España y el Reino Unido de Gran Bretaña e Irlanda del Norte), y comprender los cambios estratégicos en el precio y volumen comercializado. Se va a construir una matriz de competitividad del TradecAN elaborada por la Comisión Económica para América Latina y el Caribe (CEPAL), y que ya ha sido utilizada en otros estudios (Dussel, 2001; Clemente, 2001; Toro y Ruiz, 2005; Matesanz y Sánchez Díez, 2005; Romo Murillo, 2007; Ponce, Contreras y Vásquez, 2007; Sánchez Díez y Villalobos Álvarez, 2010). Para medir la competitividad de un país respecto de un producto se relacionan dos variables: el factor exógeno y el endógeno. El primero de estos - factor exógeno- tiene que ver con los cambios en el mercado internacional y el segundo - factor endógeno- se relaciona con la habilidad de cada país para responder a las alteraciones en la primera variable, ya sea mediante el aumento o la disminución de sus exportaciones, dependiendo de la dinámica del producto. La matriz en el eje horizontal (X) mide el comportamiento del primer factor, mientras que en el eje vertical (Y) se mide el segundo factor. La relación entre estas dos variables permite distinguir cuatro situaciones diferentes de esta: estrella menguante; estrella naciente; retiradas y oportunidades perdidas.

\section{b) Estados Unidos de América}

Es un mercado dependiente de la importación debido a la menor producción local y al aumento del consumo. El espárrago mexicano, como "estrella naciente", domina la oferta todo el año (veánse los gráficos 6 y 7). En el segundo semestre el comercio representa el 58\% del volumen anual de abastecimiento internacional, mientras que de julio a diciembre representa el $42 \%$. México vende el $20 \%$ de sus espárragos en el segundo semestre, mientras que para el Perú el espárrago representa el $80 \%$ del despacho.

El espárrago del Perú, por incremento de sus costos en dólares ante el fortalecimiento de su moneda local (véase el gráfico 2), debe presionar por aumentar su precio CIF de exportación, a diferencia de México (véanse los gráficos 8 y 9). Mientras que el espárrago mexicano presenta otro panorama en sus precios, en el Perú se incrementa la necesidad de diversificar mercados. 
GRÁFICO 6

Estados Unidos: matriz TradecAN en primer semestre de importación, 2008-2012 (En porcentajes)

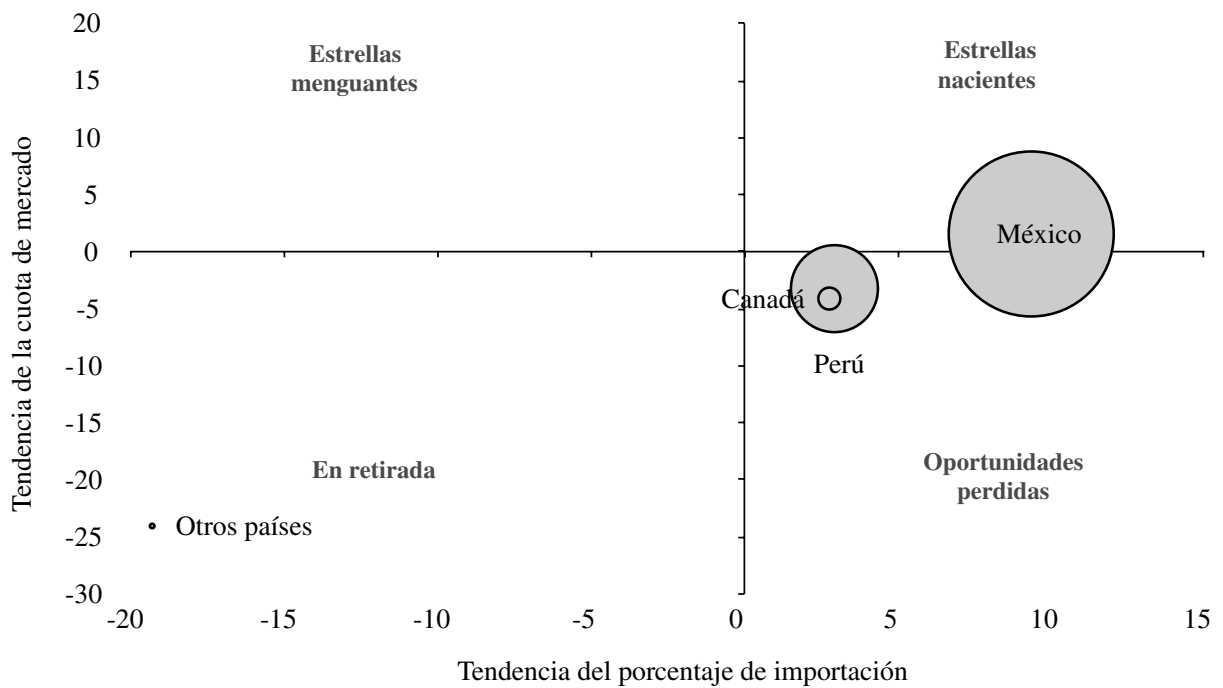

Fuente: elaboración propia sobre la base de datos del Centro de Comercio Internacional (CCI) y la Base de datos estadísticos sobre el comercio de mercaderías (COMTRADE).

GRÁFICO 7

Estados Unidos: matriz TradeCAN en segundo semestre de importación, 2008-2012 (En porcentajes)

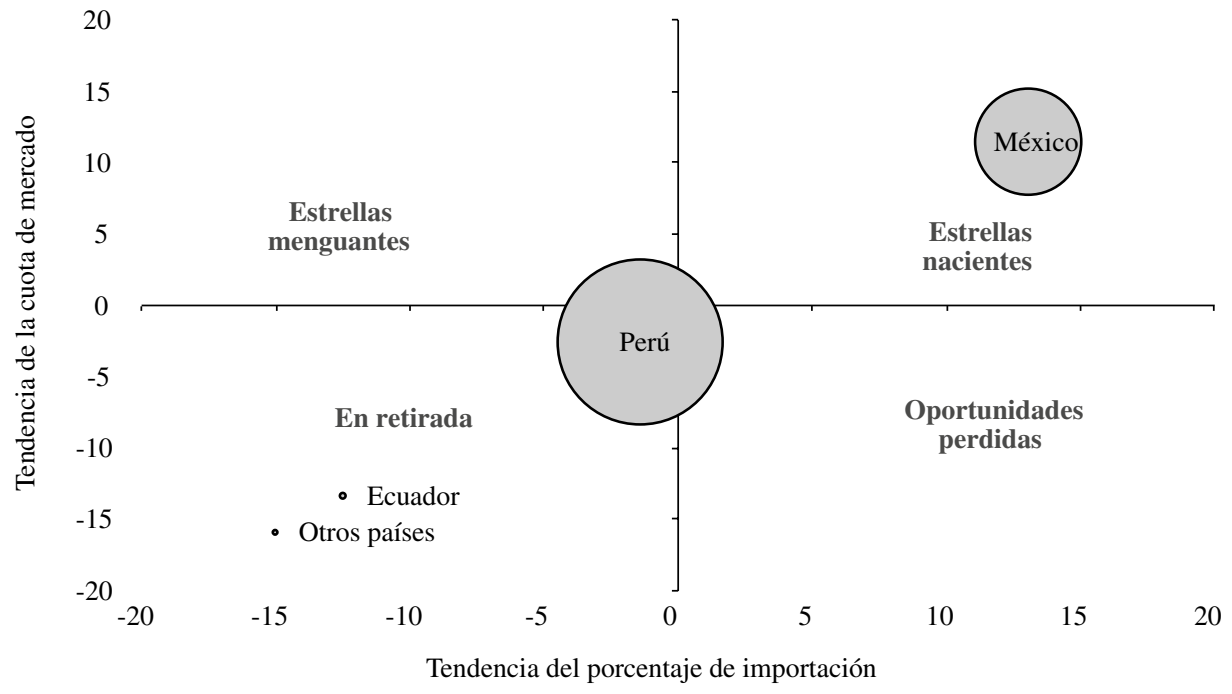

Fuente: elaboración propia sobre la base de datos del Centro de Comercio Internacional (CCI) y la Base de datos estadísticos sobre el comercio de mercaderías (COMTRADE). 
GRÁFICO 8

Estados Unidos: análisis comercial en primer semestre de importación, 2008-2012 (En porcentajes)

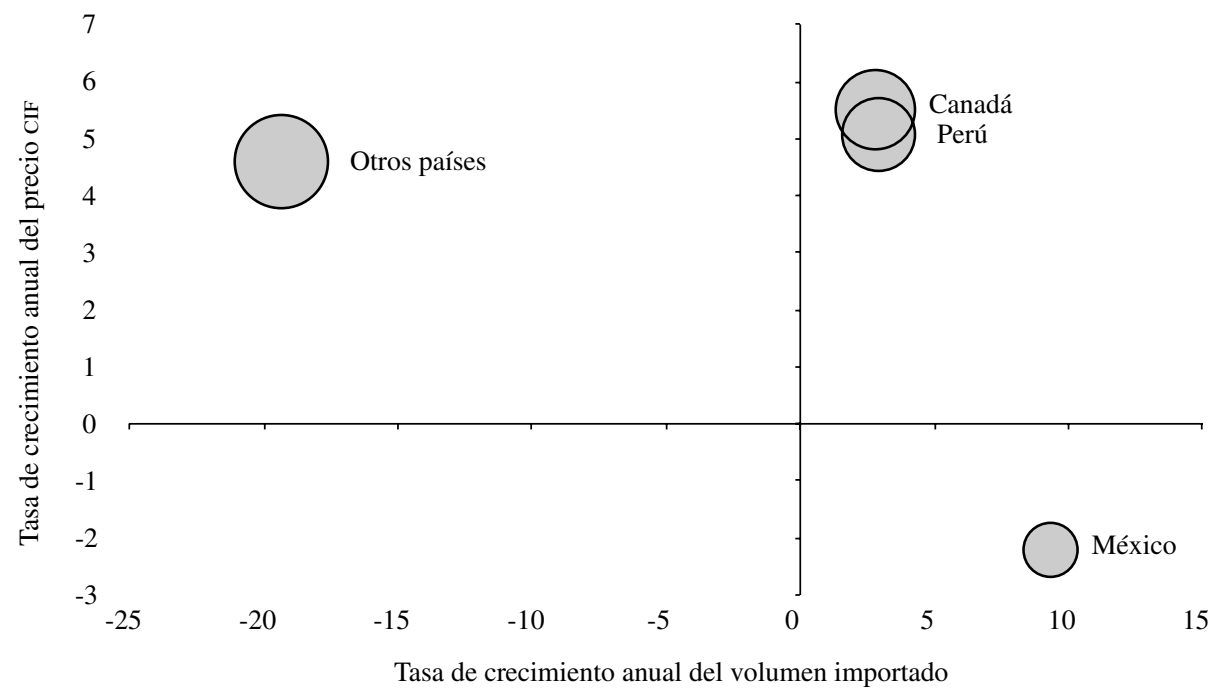

Fuente: elaboración propia sobre la base de datos del Centro de Comercio Internacional (CCI) y la Base de datos estadísticos sobre el comercio de mercaderías (COMTRADE).

CIF: precio de costo, seguro y fletes.

GRÁFICO 9

Estados Unidos: análisis comercial en segundo semestre de importación, 2008-2012 (En porcentajes)

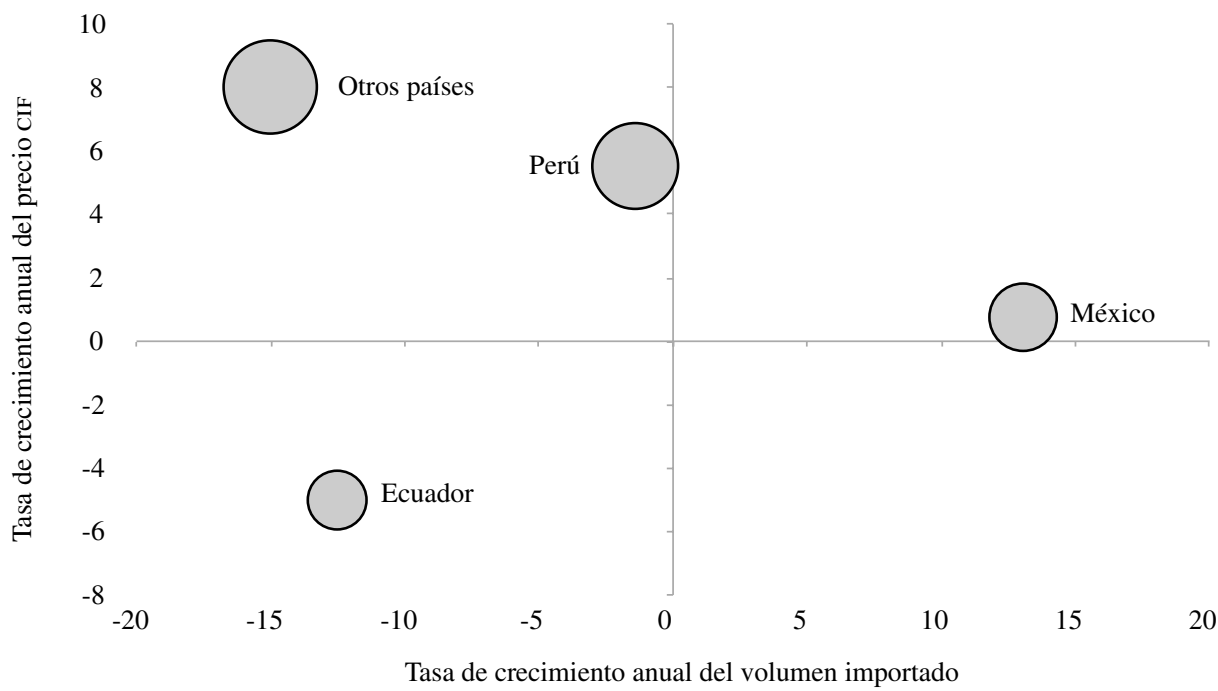

Fuente: elaboración propia sobre la base de datos del Centro de Comercio Internacional (CCI) y la Base de datos estadísticos sobre el comercio de mercaderías (COMTRADE).

CIF: precio de costo, seguro y fletes. 
Los precios del segundo semestre (véase el cuadro 11) por lo general son superiores a los del primero; particularmente el costo de la logística para exportación, mientras que los gastos comerciales y de intermediación se han mantenido estables. Esto explica que el precio minorista o al consumidor en los Estados Unidos de América no tenga un incremento proporcional al alza de precios de exportación o precios FOB, lo que se deriva del problema de la paridad cambiaria en el Perú y su repercusión en los costos en dólares.

\section{c) Holanda}

El 55\% de las importaciones anuales durante 2012 correspondieron al primer semestre, mientras que el $45 \%$ al segundo. En el primer período, la tendencia del volumen de compras se redujo anualmente a una tasa de un 11,2\% en el lapso 2008-2012. La producción local de espárragos se verifica entre los meses de abril y julio, con tendencia positiva, dado que varió de 14.000 a 17.000 toneladas en el período analizado, lo que explica la desaceleración de la importación en el primer semestre.

El espárrago griego, que tenía una cuota de mercado de un $12 \%$, ahora la ha visto reducida a un $1 \%$, mientras que Alemania pasó del $57 \%$ a un $3 \%$ en 2012, reorientando las ventas al mercado suizo de la oferta temprana y central del período de su cosecha. Ese espacio del primer semestre lo ocuparon las ofertas de México y el Perú, lo que explica su posición de "estrella naciente", mientras que Alemania y Grecia se ubican en "retirada" (véase el gráfico 10).

En el segundo semestre la tasa media anual de crecimiento de abastecimiento en el período 2008 a 2012 es de un $5,7 \%$, a diferencia de los primeros meses del año. Perú domina la segunda parte del año, con el $93 \%$ de cuota de mercado, mientras que surgen pequeños cambios en los proveedores, como son el crecimiento de Alemania y España que se posicionan como "estrellas nacientes" con la oferta en la etapa tardía de su cosecha, desplazando a las ventas de Tailandia y otros países -particularmente el Reino Unido y Bélgica-, que se posicionan ahora en "retirada" (véase el gráfico 11).

En el primer semestre, las ventas de Alemania y Grecia se vinculan a una oferta más selectiva y con incremento de precios (véase el gráfico 12), a diferencia del avance de México y el Perú que no se convalida con un aumento significativo de precios, dado que estos variaron entre un $1,6 \%$ y un $1 \%$ anual, respectivamente.

Mientras que en el segundo semestre el incremento de la mejora de precios CIF también se observa en el Perú, y además en Alemania y España (véase el gráfico 13).

El aumento del precio CIF de importación del espárrago peruano en Holanda se explica mayormente por el acrecentamiento del costo de la logística internacional, tanto en el primer como en el segundo semestres, debido al incremento del precio FOB en origen (véase el cuadro 12).

Estados Unidos: precios del comercio del espárrago peruano, 2008-2012 (Dólares por kilogramo)

\begin{tabular}{|c|c|c|c|c|c|c|}
\hline Julio a diciembre & 2008 & 2009 & 2010 & 2011 & 2012 & $\begin{array}{l}\text { Variación anual } \\
\text { (en porcentajes) }\end{array}$ \\
\hline Precio fOB Perú & 1,79 & 1,80 & 2,48 & 2,18 & 2,67 & 6,5 \\
\hline - Logística & 0,84 & 0,86 & 0,94 & 1,02 & 1,01 & 3,5 \\
\hline Precio CIF en Estados Unidos & 2,62 & 2,65 & 3,42 & 3,20 & 3,69 & 5,6 \\
\hline - Comercialización & 3,46 & 2,80 & 2,36 & 3,09 & 3,01 & $-1,2$ \\
\hline Retail en Estados Unidos & 6,09 & 5,46 & 5,77 & 6,28 & 6,70 & 2,1 \\
\hline Enero a junio & 2008 & 2009 & 2010 & 2011 & 2012 & $\begin{array}{l}\text { Variación anual } \\
\text { (en porcentajes) }\end{array}$ \\
\hline Precio foB Perú & 1,94 & 1,94 & 1,93 & 2,07 & 2,74 & 5,2 \\
\hline - Logística & 0,71 & 0,72 & 0,83 & 0,90 & 0,92 & 4,7 \\
\hline Precio CIF en Estados Unidos & 2,65 & 2,66 & 2,76 & 2,97 & 3,66 & 5,1 \\
\hline - Comercialización & 2,88 & 2,59 & 2,63 & 3,17 & 2,66 & 0,3 \\
\hline Retail en Estados Unidos & 5,54 & 5,25 & 5,38 & 6,14 & 6,32 & 2,7 \\
\hline
\end{tabular}

Fuente: elaboración propia sobre la base de datos de la Superintendencia Nacional de Aduanas y de Administración Tributaria (sunAT) del Perú, el Departamento de Agricultura de los Estados Unidos de América y la Base de datos estadísticos sobre el comercio de mercaderías (COMTRADE).

CIF: precio de costo, seguro y fletes.

FOB: precio puesto a bordo. 
GRÁFICO 10

Holanda: matriz TradecAN en primer semestre de importación, 2008-2012 (En porcentajes)

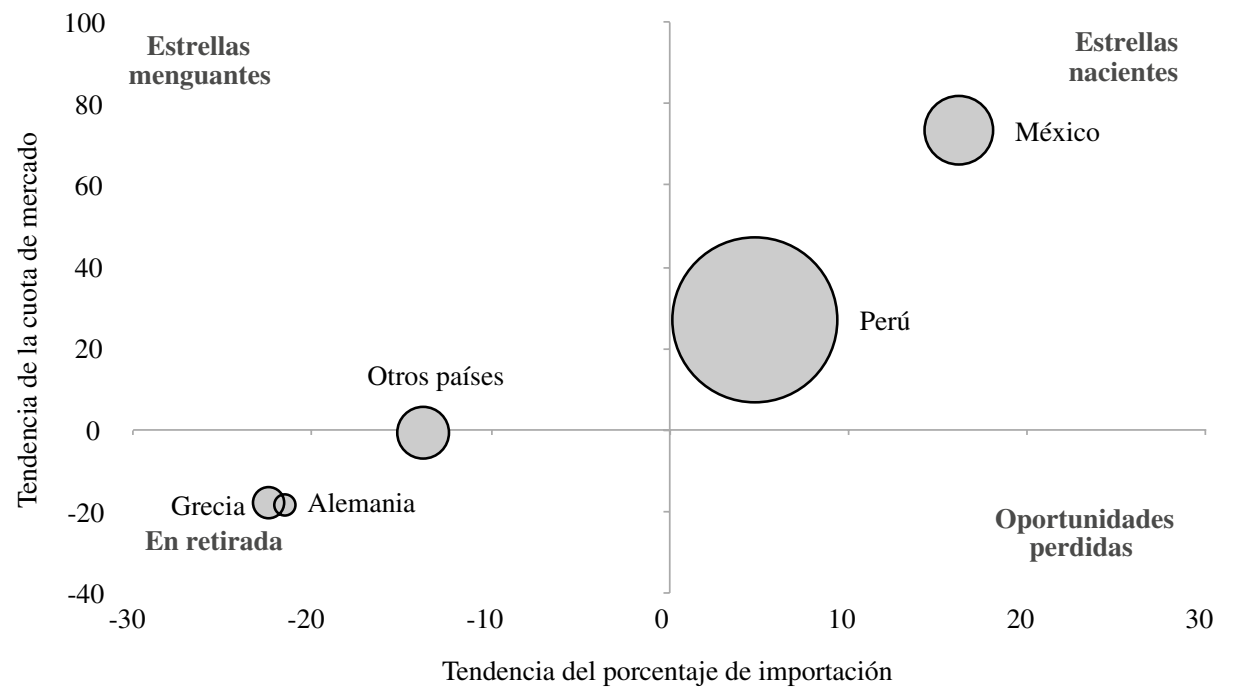

Fuente: elaboración propia sobre la base de datos del Centro de Comercio Internacional (CCI) y la Base de datos estadísticos sobre el comercio de mercaderías (COMTRADE).

GRÁFICO 11

Holanda: Matriz TradecAN en segundo semestre de importación, 2008-2012

(En porcentajes)

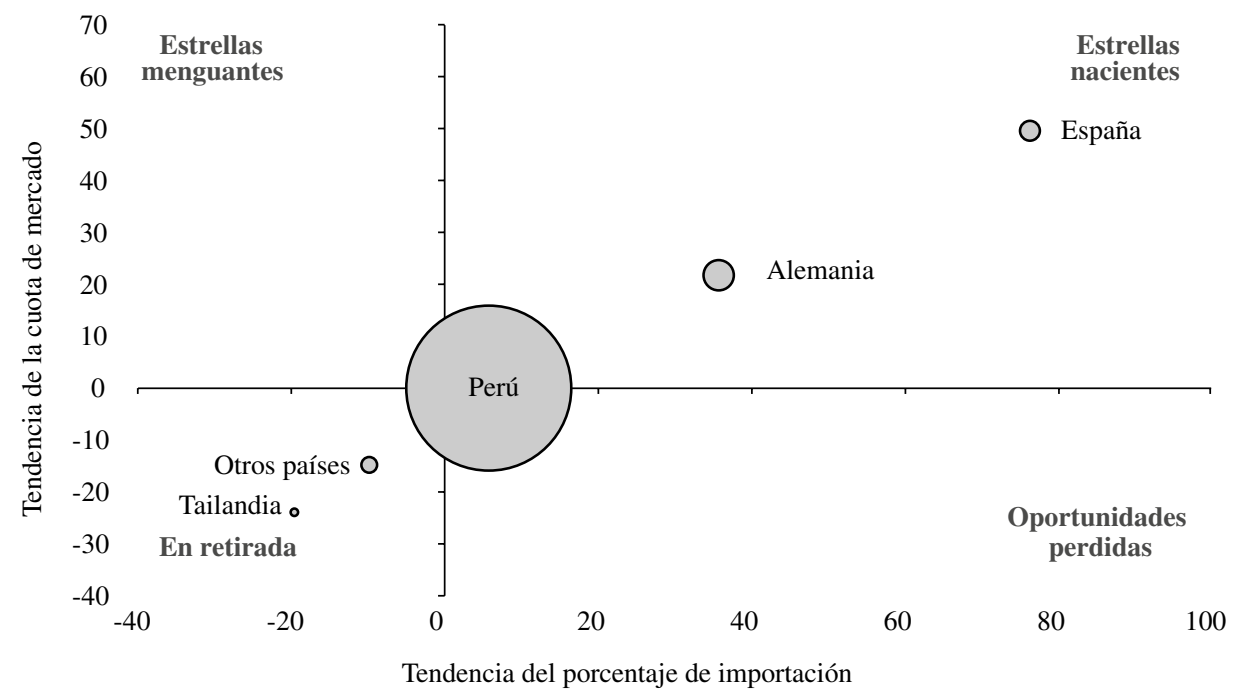

Fuente: elaboración propia sobre la base de datos del Centro de Comercio Internacional (CCI) y la Base de datos estadísticos sobre el comercio de mercaderías (COMTRADE). 
GRÁFICO 12

Holanda: análisis comercial en primer semestre de importación, 2008-2012 (En porcentajes)

20

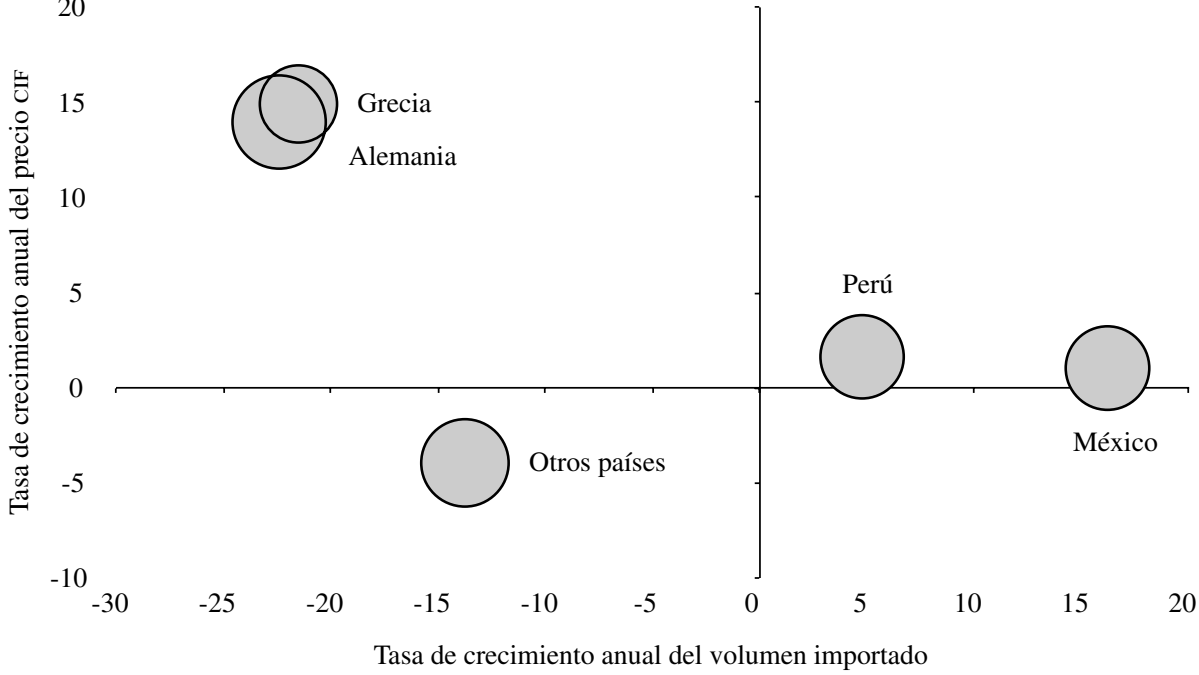

Fuente: elaboración propia sobre la base de datos del Centro de Comercio Internacional (CCI) y la Base de datos estadísticos sobre el comercio de mercaderías (COMTRADE).

CIF: precio de costo, seguro y fletes.

GRÁFICO 13

Holanda: análisis comercial en segundo semestre de importación, 2008-2012 (En porcentajes)

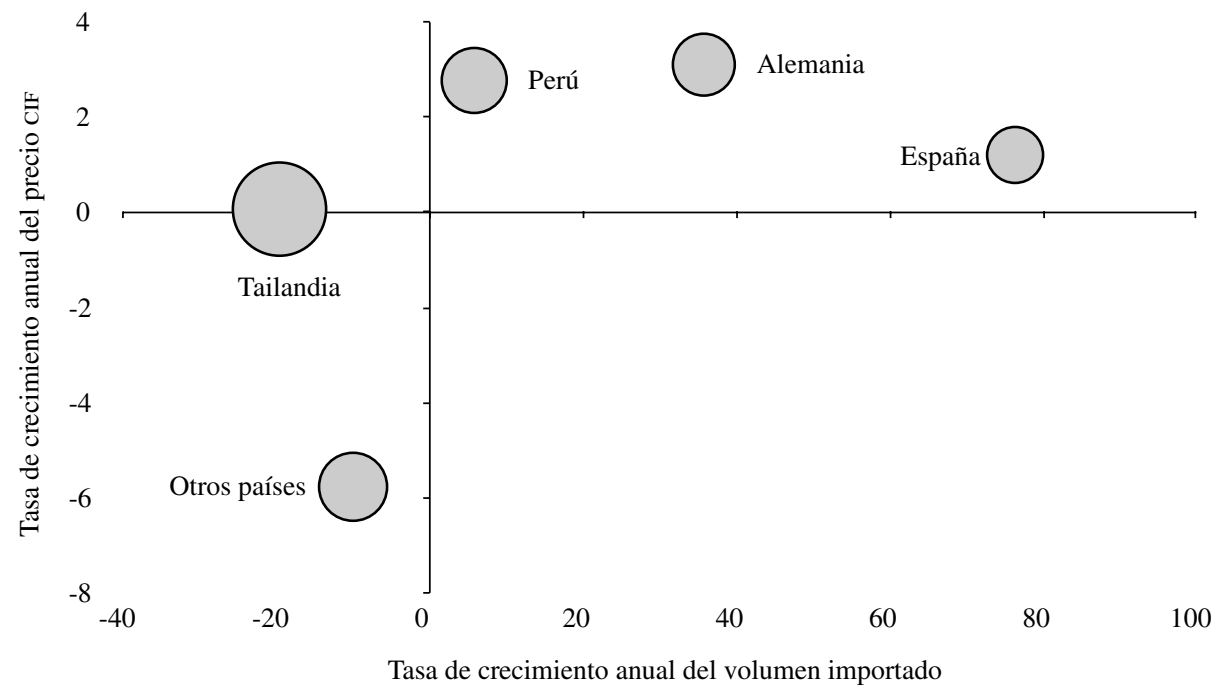

Fuente: elaboración propia sobre la base de datos del Centro de Comercio Internacional (CcI) y la Base de datos estadísticos sobre el comercio de mercaderías (COMTRADE).

CIF: precio de costo, seguro y fletes. 
CUADRO 12

Holanda: precios del comercio del espárrago peruano, 2008-2012

(Dólares por kilogramo)

\begin{tabular}{|c|c|c|c|c|c|c|}
\hline Julio a diciembre & 2008 & 2009 & 2010 & 2011 & 2012 & $\begin{array}{l}\text { Variación anual } \\
\text { (en porcentajes) }\end{array}$ \\
\hline Precio fOB Perú & 3,05 & 2,99 & 3,44 & 3,21 & 3,25 & 1,2 \\
\hline - Logística & 1,06 & 1,01 & 1,29 & 1,23 & 1,64 & 7,3 \\
\hline Precio CIF en Holanda & 4,11 & 4,00 & 4,73 & 4,44 & 4,88 & 2,8 \\
\hline Enero a junio & 2008 & 2009 & 2010 & 2011 & 2012 & $\begin{array}{l}\text { Variación anual } \\
\text { (en porcentajes) }\end{array}$ \\
\hline Precio fOB Perú & 3,35 & 3,16 & 3,35 & 3,42 & 3,20 & $-0,1$ \\
\hline - Logística & 0,79 & 0,88 & 0,82 & 1,12 & 1,25 & 8,0 \\
\hline Precio CIF en Holanda & 4,14 & 4,04 & 4,17 & 4,54 & 4,45 & 1,6 \\
\hline
\end{tabular}

Fuente: elaboración propia sobre la base de datos de la Superintendencia Nacional de Aduanas y de Administración Tributaria (suNAT) del Perú, el Departamento de Agricultura de los Estados Unidos de América y la Base de datos estadísticos sobre el comercio de mercaderías (COMTRADE).

CIF: precio de costo, seguro y fletes.

FOB: precio puesto a bordo.

\section{d) España}

La producción de espárragos en España se cosecha en el primer semestre, cosecha que ha crecido de 44.000 a 58.000 toneladas entre los años 2008 y 2011. El volumen de importación de este mercado se reparte en partes iguales entre el primer y el segundo semestres, evidenciando, sin embargo, un mayor consumo de enero a junio debido a la cosecha local. Las compras a Marruecos, México y Holanda corresponden al primer período del año, mientras que el Perú despacha el $41 \%$ de sus ventas de enero a junio, siendo México y Holanda las "estrellas nacientes" en este período y Marruecos aparece en "retirada" (véase el gráfico 14).

El consumo en el segundo semestre es solo de espárragos importados — donde el Perú concentra el $59 \%$ de sus envíos anuales, con una cuota de mercado del $97 \%$ de la facturación-y se manifiesta una pequeña oferta del Ecuador como "estrella naciente", ocupando el espacio que dejan en "retirada" las ofertas de Marruecos y de Francia (véase el gráfico 15).

La estrategia comercial es una política de ajuste de precios en el primer semestre (véase el gráfico 16), más en el caso del espárrago comercializado desde Holanda que en relación con el de México.

La mejora de posición del Perú se explica por el aumento de precios y con ello de la facturación, ante un leve incremento del volumen. Esto explica por qué el precio CIF creció a una tasa anual promedio de un $2,6 \%$ (véase el gráfico 17), presionado por el alza de sus costos internos ante la evolución de la paridad real de su moneda frente al dólar estadounidense. Es muy probable que el incremento de precios en el espárrago importado desde el Perú actué como un limitante para el crecimiento de las ventas en el segundo semestre, lo que explicaría por qué las ventas se mantienen estables en volumen entre los años 2008 y 2012.

En resumen, el precio CIF del espárrago peruano en España en el primer semestre tiende a incrementarse por la combinación de un mayor precio ғOB y un alza de costos de la logística internacional. Sin embargo, en el segundo semestre la variación del precio CIF se explica solo por el alza del precio ғOB (véase el cuadro 13). 
GRÁFICO 14

España: matriz TradecAN en primer semestre de importación, 2008-2012 (En porcentajes)

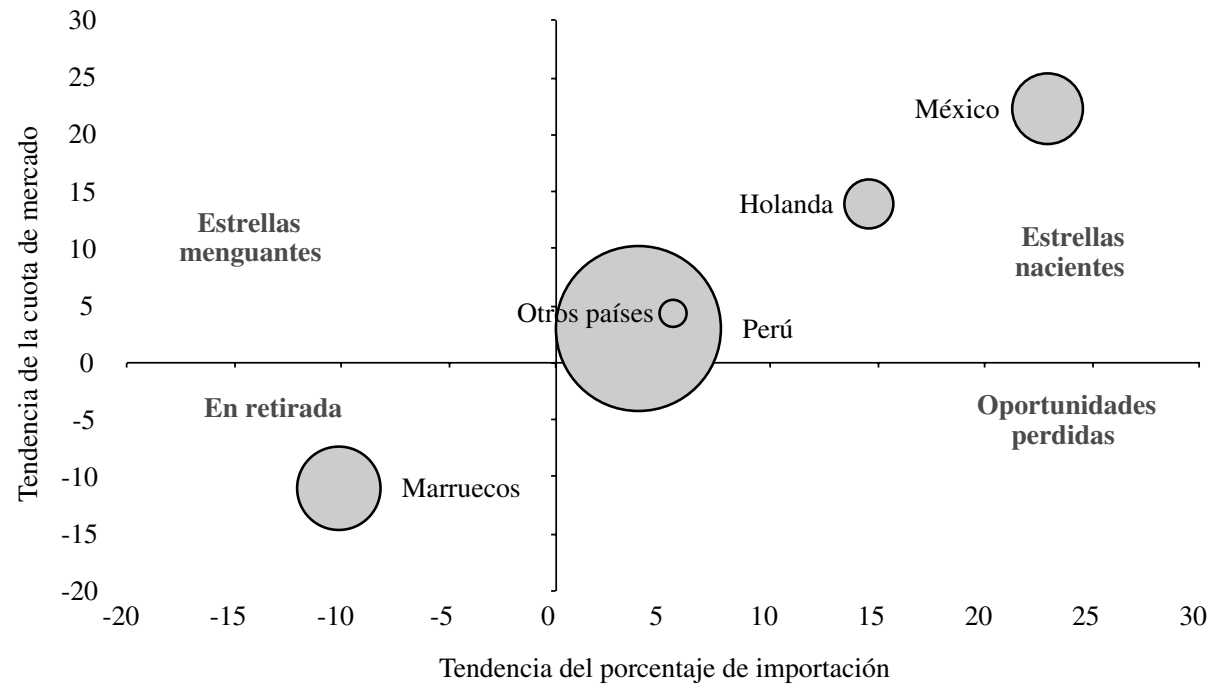

Fuente: elaboración propia sobre la base de datos del Centro de Comercio Internacional (CCI) y la Base de datos estadísticos sobre el comercio de mercaderías (COMTRADE).

GRÁFICO 15

España: matriz TradecAN en segundo semestre de importación, 2008-2012 (En porcentajes)

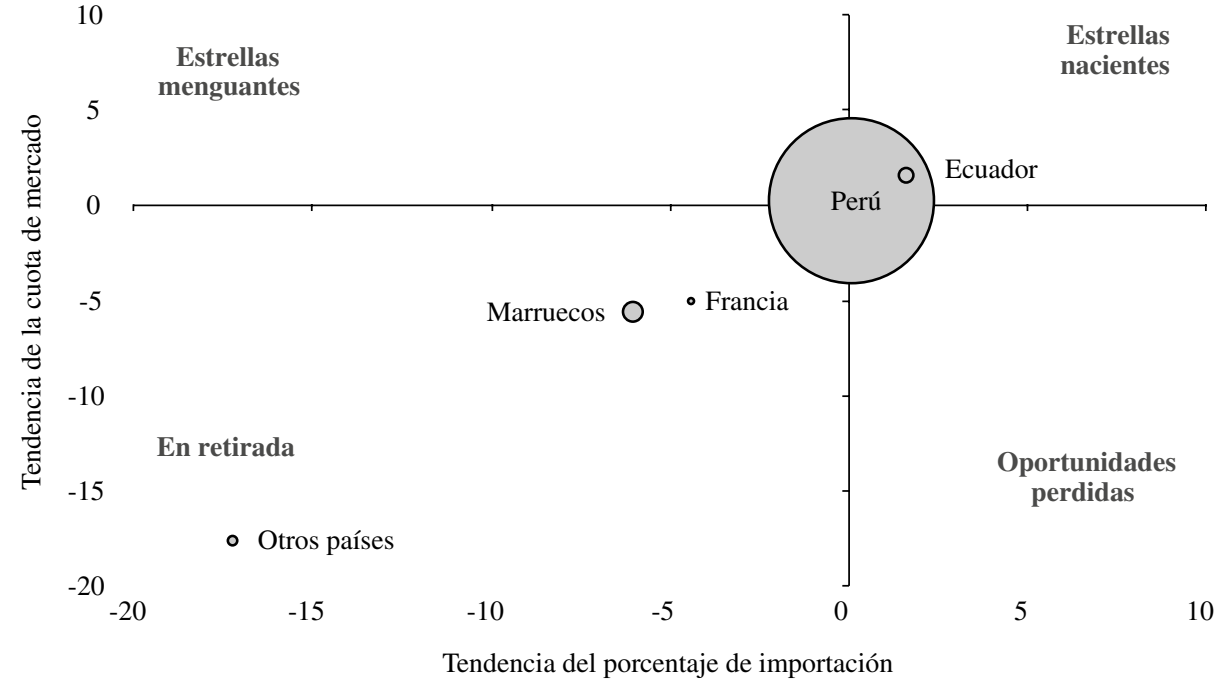

Fuente: elaboración propia sobre la base de datos del Centro de Comercio Internacional (CCI) y la Base de datos estadísticos sobre el comercio de mercaderías (COMTRADE). 
GRÁFICO 16

España: análisis comercial en primer semestre de importación, 2008-2012 (En porcentajes)

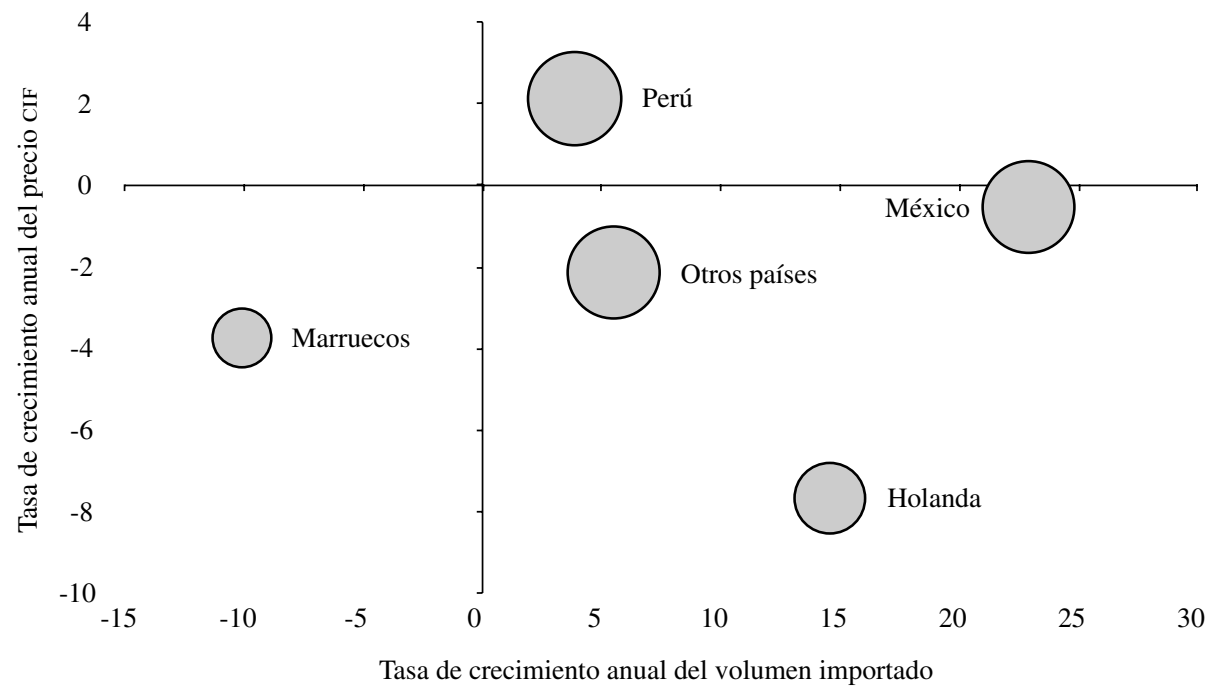

Fuente: elaboración propia sobre la base de datos del Centro de Comercio Internacional (CCI) y la Base de datos estadísticos sobre el comercio de mercaderías (COMTRADE).

CIF: precio de costo, seguro y fletes.

GRÁFICO 17

España: análisis comercial en segundo semestre de importación, 2008-2012 (En porcentajes)

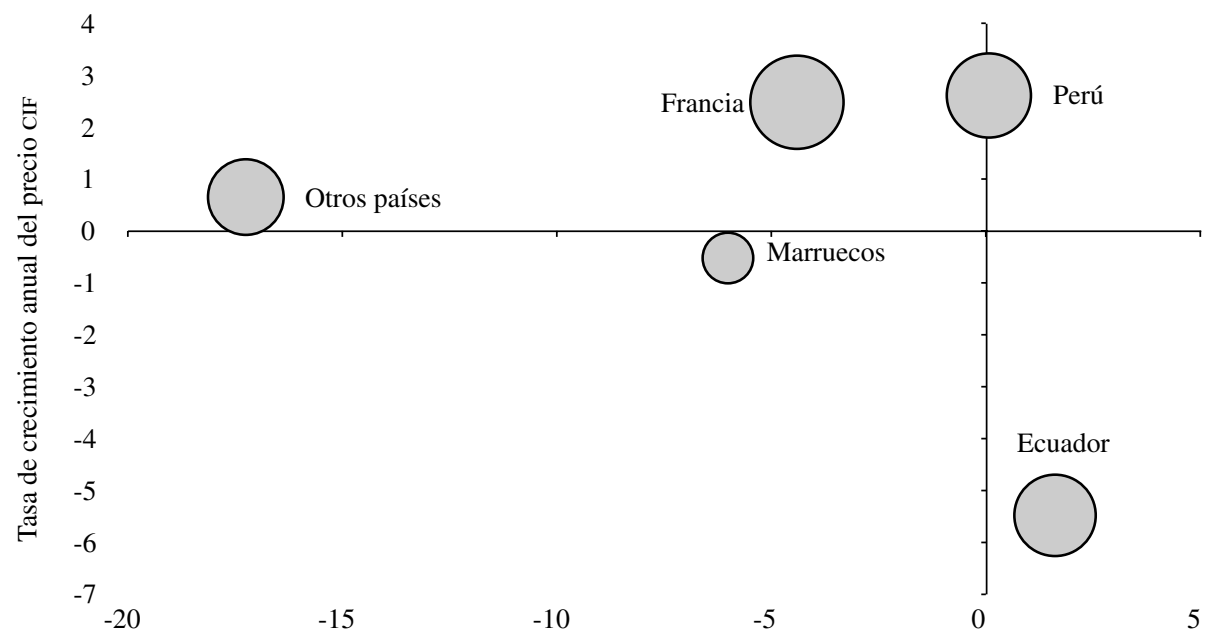

Tasa de crecimiento anual del volumen importado

Fuente: elaboración propia sobre la base de datos del Centro de Comercio Internacional (CCI) y la Base de datos estadísticos sobre el comercio de mercaderías (COMTRADE).

CIF: precio de costo, seguro y fletes. 
España: precios del comercio del espárrago peruano, 2008-2012

(Dólares por kilogramo)

\begin{tabular}{|c|c|c|c|c|c|c|}
\hline Julio a diciembre & 2008 & 2009 & 2010 & 2011 & 2012 & $\begin{array}{l}\text { Variación anual } \\
\text { (en porcentajes) }\end{array}$ \\
\hline Precio FOB Perú & 1,97 & 2,09 & 2,64 & 2,39 & 2,89 & 5,8 \\
\hline Precio CIF en España & 4,10 & 4,06 & 4,23 & 4,40 & 4,84 & 2,6 \\
\hline Enero a junio & 2008 & 2009 & 2010 & 2011 & 2012 & $\begin{array}{l}\text { Variación anual } \\
\text { (en porcentajes) }\end{array}$ \\
\hline Precio FOB Perú & 2,10 & 2,12 & 2,14 & 2,27 & 2,63 & 3,4 \\
\hline - Logística & 1,89 & 1,71 & 3,10 & 3,31 & 3,36 & 12,1 \\
\hline Precio CIF en España & 3,99 & 3,83 & 5,24 & 5,58 & 5,99 & 7,8 \\
\hline
\end{tabular}

Fuente: elaboración propia sobre la base de datos de la Superintendencia Nacional de Aduanas y de Administración Tributaria (sunAT) del Perú, el Departamento de Agricultura de los Estados Unidos de América y la Base de datos estadísticos sobre el comercio de mercaderías (COMTRADE).

CIF: precio de costo, seguro y fletes.

FOB: precio puesto a bordo.

\section{e) Reino Unido de Gran Bretaña e Irlanda del Norte}

Los beneficios para la salud derivados del consumo de vegetales, particularmente el espárrago en relación con los diabéticos ${ }^{5}$, sostienen con fuerza su consumo en el Reino Unido de Gran Bretaña e Irlanda del Norte. El abastecimiento importado representa el $46 \%$ de la importación anual para el período de enero a junio - complementado mediante la oferta local de abril a junio y el aumento de producción local de 32.000 a 51.000 toneladas entre 2008 y $2011-$, mientras que la importación alcanza al $54 \%$ de las compras anuales entre los meses de julio a diciembre.

Las ventas de México representan el 98\% del envío anual a este mercado en el primer semestre, mientras que para el Perú representan el 30\%, dado que el $70 \%$ lo comercializa desde julio a diciembre. Nuevamente aparece México como "estrella naciente", además de Italia, en el primer semestre (véase el gráfico 18) debido al incremento de sus ventas, mientras que se ubican en "retirada" las ofertas de España y el Perú.

El segundo semestre es dominado por el abastecimiento desde el Perú, mientras que la oferta reducida de Holanda se posiciona en "estrella naciente" —desconociéndose el origen de esa producción—, ocupando

\footnotetext{
${ }^{5}$ http://www.dailymail.co.uk/health/article-2236322/Asparagus-trendy-vegetable-fights-diabetes.html.
}

el espacio en "retirada" de Kenya y Tailandia (véase el gráfico 19).

En el primer semestre, la posición en "retirada" del Perú se explica por el propósito de conseguir mejores precios de venta FOB, mientras que Italia avanza a "estrella naciente" con una política a la baja de sus precios (véase el gráfico 20).

El caso de España es en "retirada" de enero a junio, tanto por menor volumen como debido a la baja de sus precios. Por otra parte, en el segundo semestre, el caso de Kenya es similar a lo observado para España en el primer semestre, mientras que Tailandia disminuye su volumen, pero logra mejorar sus precios FOB, en tanto que la "estrella naciente" de Holanda significa más volumen y mejora de sus precios (véase el gráfico 21).

En el segundo semestre también se observa una mejora del precio CIF del Perú y, por lo tanto, dicho incremento es un factor que bien puede explicar la estabilidad del consumo en el Reino Unido de Gran Bretaña e Irlanda del Norte.

Ahora bien, una particularidad en el Reino Unido, a diferencia de lo observado en el mercado de los Estados Unidos de América, es que el aumento del precio CIF de importación del espárrago peruano obedece sobre todo al incremento del costo de la logística internacional, tanto en el primer como en el segundo semestres, debido al alza del precio FOB en origen (véase el cuadro 14). Hay que señalar que la paridad del euro frente al dólar también ayudó a absorber parte de los mayores costos internos en dólares en este período analizado. 
GRÁFICO 18

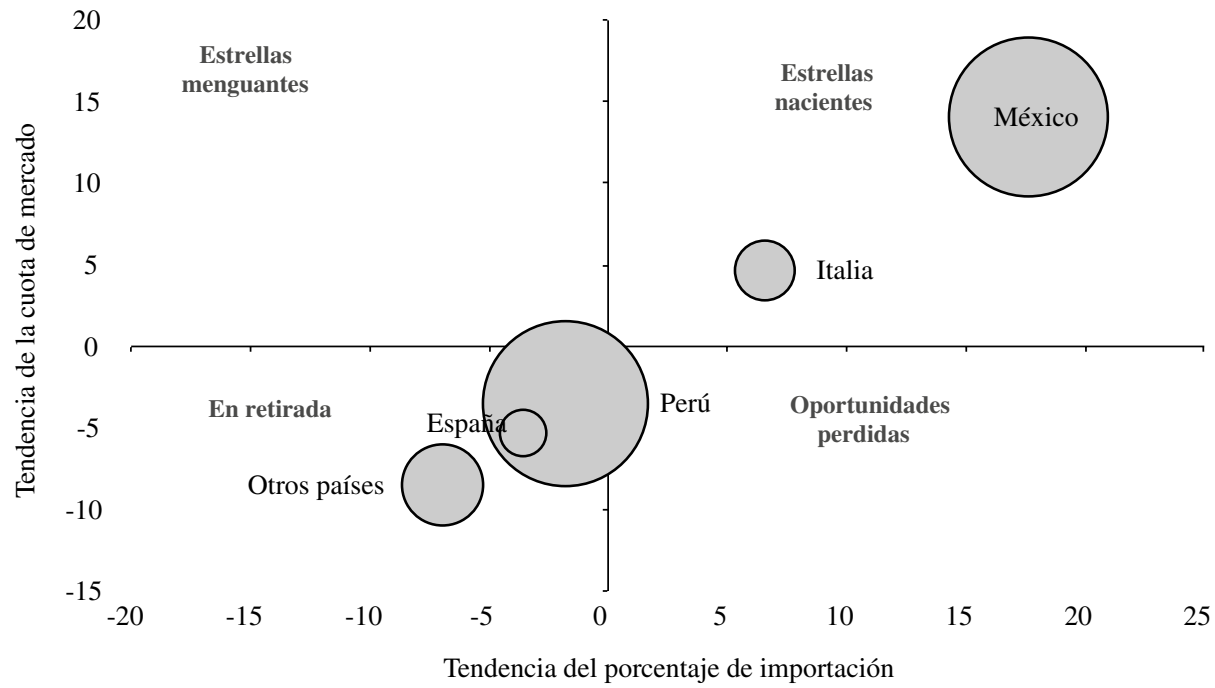

Fuente: elaboración propia sobre la base de datos del Centro de Comercio Internacional (CCI) y la Base de datos estadísticos sobre el comercio de mercaderías (COMTRADE).

GRÁFICO 19

Reino Unido: matriz TradecAN en segundo semestre de importación, 2008-2012

(En porcentajes)

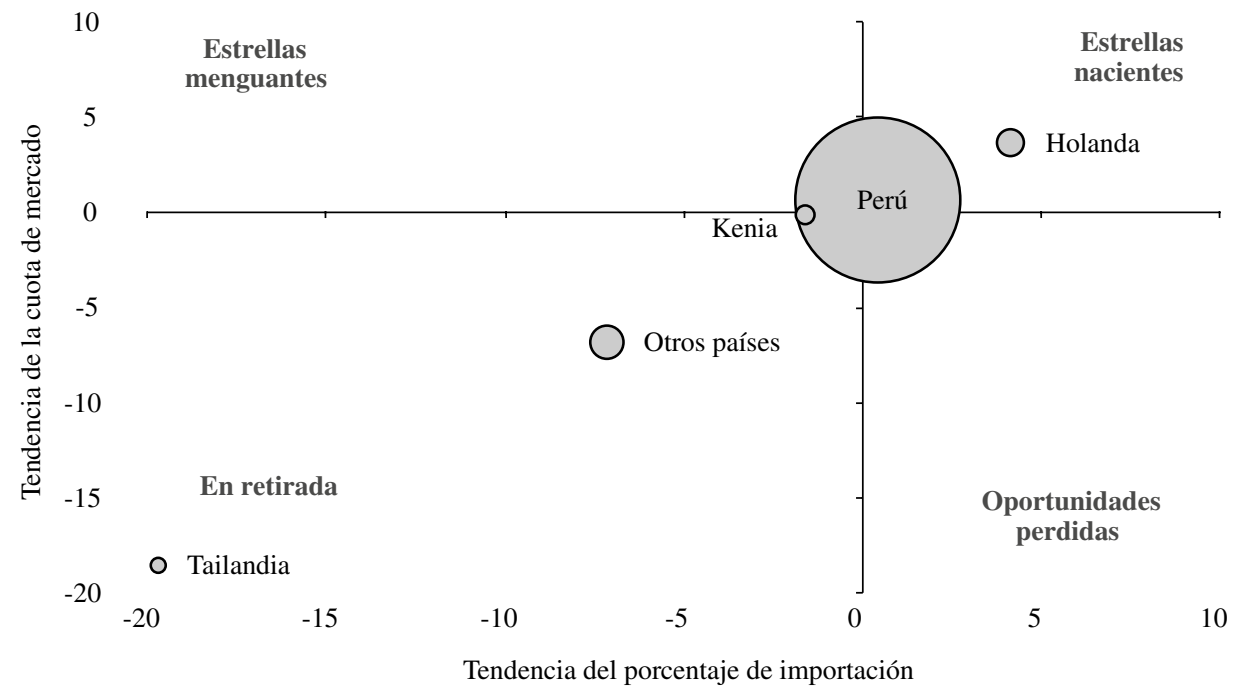

Fuente: elaboración propia sobre la base de datos del Centro de Comercio Internacional (CCI) y la Base de datos estadísticos sobre el comercio de mercaderías (COMTRADE). 
GRÁFICO 20

Reino Unido: análisis comercial en primer semestre de importación, 2008-2012 (En porcentajes)

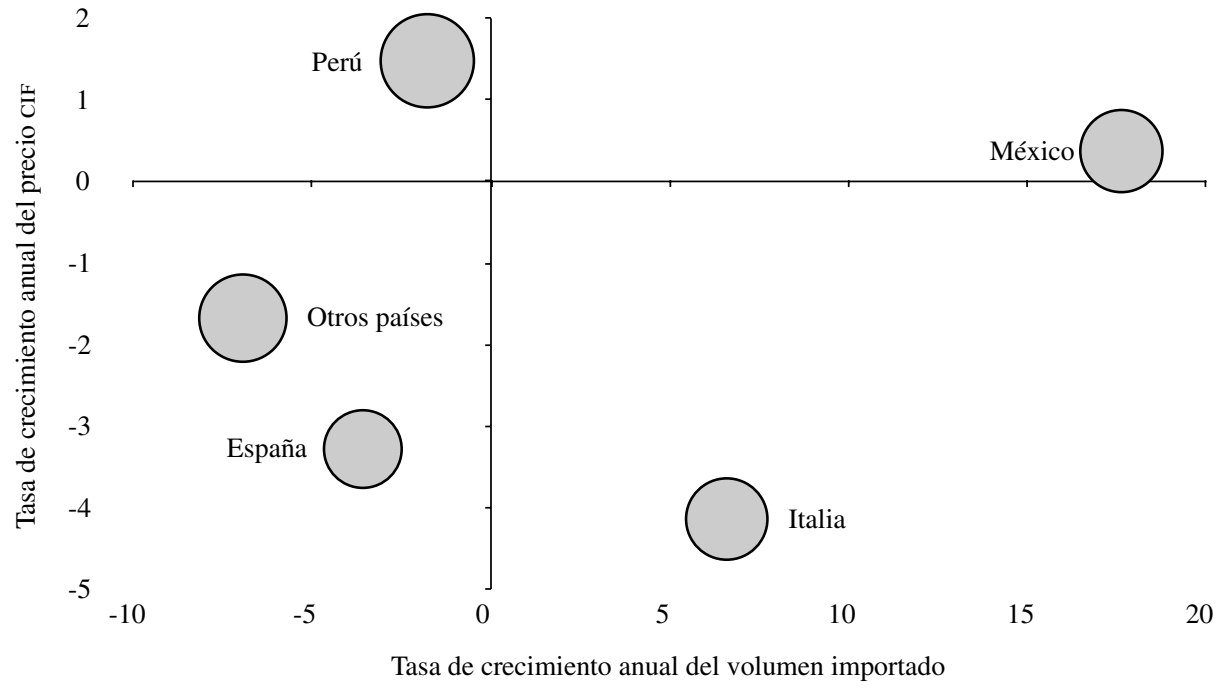

Fuente: elaboración propia sobre la base de datos del Centro de Comercio Internacional (CCI) y la Base de datos estadísticos sobre el comercio de mercaderías (COMTRADE).

CIF: precio de costo, seguro y fletes.

GRÁFICO 21

Reino Unido: análisis comercial en segundo semestre de importación, 2008-2012 (En porcentajes)

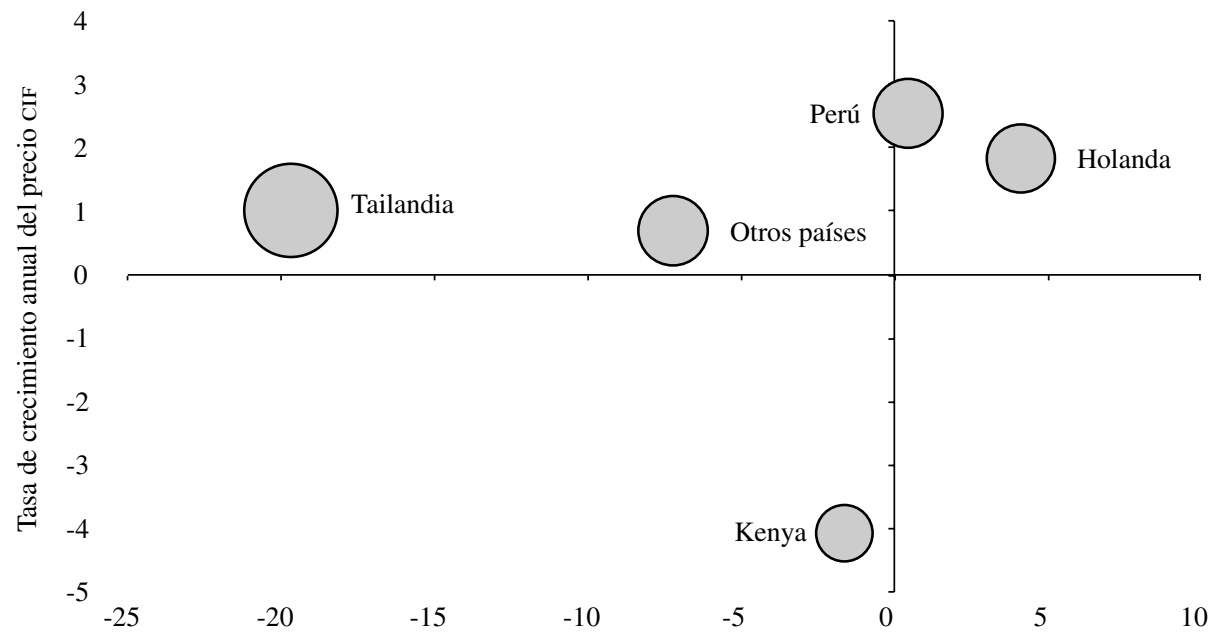

Tasa de crecimiento anual del volumen importado

Fuente: elaboración propia sobre la base de datos del Centro de Comercio Internacional (CCI) y la Base de datos estadísticos sobre el comercio de mercaderías (COMTRADE).

CIF: precio de costo, seguro y fletes. 
CUADRO 14

Reino Unido: precios del comercio del espárrago peruano, 2008-2012 (Dólares por kilogramo)

\begin{tabular}{|c|c|c|c|c|c|c|}
\hline Julio a diciembre & 2008 & 2009 & 2010 & 2011 & 2012 & $\begin{array}{l}\text { Variación anual } \\
\text { (en porcentajes) }\end{array}$ \\
\hline Precio fOB Perú & 2,93 & 3,17 & 3,60 & 3,19 & 3,16 & 0,9 \\
\hline - Logística & 1,77 & 1,81 & 1,78 & 2,33 & 2,33 & 5,3 \\
\hline Precio CIF en Reino Unido. & 4,70 & 4,98 & 5,38 & 5,52 & 5,49 & 2,5 \\
\hline Enero a junio & 2008 & 2009 & 2010 & 2011 & 2012 & $\begin{array}{l}\text { Variación anual } \\
\text { (en porcentajes) }\end{array}$ \\
\hline Precio FOB Perú & 3,58 & 3,19 & 3,09 & 3,40 & 3,11 & $-1,3$ \\
\hline - Logística & 1,85 & 1,92 & 2,15 & 2,18 & 2,88 & 7,0 \\
\hline Precio CIF en Reino Unido & 5,43 & 5,11 & 5,24 & 5,58 & 5,99 & 1,8 \\
\hline
\end{tabular}

Fuente: elaboración propia sobre la base de datos de la Superintendencia Nacional de Aduanas y de Administración Tributaria (suNAT) del Perú, el Departamento de Agricultura de los Estados Unidos de América y la Base de datos estadísticos sobre el comercio de mercaderías (COMTRADE).

CIF: precio de costo, seguro y fletes.

FOB: precio puesto a bordo.

\section{Conclusiones}

En los últimos años, el Perú es el incuestionable líder mundial en la exportación del espárrago. Sus exportaciones tienden a la diversificación comercial, aunque sigue dominando la venta a los Estados Unidos de América, pero con tendencia negativa (véase el gráfico 1).

Son de gran importancia los cambios detectados en el comercio internacional de espárragos peruanos, conformando lo que sustenta un nuevo modelo denominado sistema complejo adaptativo en el marco de la quinta revolución tecnológica.

En primer término hay que mencionar la atomización de la estructura, con baja concentración económica (véase el cuadro 7), particularmente en las exportaciones de espárragos a los Estados Unidos de América y Europa, que son los principales destinos comerciales. La atomización del sector exportador se debe al aumento de empresas (véase el cuadro 9) y a la menor cuota de mercado de las empresas líderes que se están diversificando a otros productos exportables (uva de mesa, palta, granada y arándanos), como es el caso de Camposol, por ejemplo. $\mathrm{Al}$ estudiar a los importadores también se observa ese proceso de atomización (véase el cuadro 8) por la vía marítima, y particularmente para las ventas al mercado de los Estados Unidos de América. Algo que también se observa en el estudio de caso de la exportación de frutas en Chile.
Otra cuestión que surge es la baja similitud de las políticas comerciales de las principales exportadoras (véase el gráfico 3), lo que valida el paradigma de mercado segmentado. Ahora bien, atomización de la estructura y baja similitud en las políticas comerciales son elementos que sustentan al sistema complejo adaptativo y, con ello, un novedoso proceso de adaptación a los cambios del comercio mundial como característica en esta nueva revolución tecnológica.

La competencia del Perú es la oferta de espárragos mexicana — que se ubica como "estrella naciente" (véase el gráfico 18) en varios países durante el primer semestre, tales como el Reino Unido, Holanda (véase el gráfico 10) y España (véase el gráfico 14), y además todo el año en los Estados Unidos de América (véanse los gráficos 6 y 7)—, facilitada por la paridad del peso mexicano frente al dólar estadounidense (véase el gráfico 2).

El segundo semestre es donde el Perú concentra sus mayores ventas, en tanto que se observa cierto estancamiento en España (véase el gráfico 17), además de algunos pequeños competidores en crecimiento en Holanda (véase el gráfico 13: Alemania y España) y el Reino Unido (véase el gráfico 21: Holanda).

La dinámica del mercado, la competencia de México, el crecimiento de los costos de logística, la variación de las monedas y la baja similitud en las 
políticas comerciales de las exportadoras, evidencian que en este sistema complejo adaptativo se necesita tomar cada vez más y mejores decisiones, y que resulta un factor clave la información ágil y estratégica. Incluso el cambio climático influye crecientemente en el negocio del espárrago, tanto en las zonas productivas como en las de los consumidores, ya sea por efecto de las temperaturas como por las lluvias o sequías. Pero sin duda, una limitante al modelo de espárragos del Perú, además de lo coyuntural del clima, es la disponibilidad de agua, a pesar de las políticas públicas relativas a las infraestructuras que permitan mejorar los regadíos.

Frente a estos retos, resulta válido señalar que existen instituciones que están desarrollando esfuerzos por lograr innovaciones tecnológicas, pero que actúan aisladamente y no visualizan la necesidad de hacerlo en toda la cadena. Sin embargo, el Instituto Nacional de Innovación Agraria (INIA) es la entidad que tiene el papel de ente rector del Sistema Nacional de Innovación Agraria (SNIA) y, por lo tanto, las políticas públicas deben dirigirse al fortalecimiento de esta entidad, donde la participación del sector privado es vital para priorizar acciones y la utilización de recursos. Aunque hay casos exitosos de trabajo en equipo entre los sectores público y privado -por ejemplo, el Instituto Peruano del Espárrago, Frío Aéreo Asociación Civil y consultoras especializadas en logística y control de calidad, entidades relacionadas con el nuevo paradigma de la información y conocimientos ágiles y estratégicos-, todavía falta por hacer en la articulación sectorial, al igual que en el desarrollo de mercados como el caso de Alemania y el Japón. Los acuerdos comerciales son otro logro importante de la política pública, ahora con la vista puesta en China y la India.

La aplicación complementaria de metodologías modernas — pensadas más en la quinta revolución tecnológica para estudiar el modelo de espárragos del Perú y con ello orientar la toma de decisiones estratégicas del sector- resulta ser una herramienta eficaz, eficiente y efectiva. Se puede señalar que dichas metodologías logran mediar aquello para lo cual están diseñadas y entregar resultados con datos accesibles sobre el comercio internacional. Aunque tal vez el detalle a nivel de empresas señala que no todos los países se preocupan de elaborarlas, dificultando el análisis desagregado por exportador. Tales metodologías aportan una contribución relevante de conocimiento actual y necesario para entender los cambios y el proceso de adaptación del comercio internacional, más vinculados con la competitividad en tanto que esta es dinámica y compleja. Este paquete metodológico está constituido por el ICCE, que permite examinar la exportación de un producto -es decir, el índice de política comercial en exportación, que hace posible valorar los cambios en las ventas de las exportadoras-, y la matriz de competitividad del TradecAN para investigar acerca de la importación de un producto en un mercado en particular, con una evaluación de la competencia a través de la variación en el volumen y los precios de venta. 


\section{Bibliografía}

Alarco, G. y P. del Hierro (2010), "Crecimiento y concentración de los principales grupos empresariales en México", Revista CEPAL, $\mathrm{N}^{\circ} 101$ (LC/G.2455-P), Santiago de Chile, agosto.

Baumann, R. (2009), "El comercio entre los países "BRICs", (LC/BRS/R.210), Brasilia, oficina de la CEPAL en Brasilia [en línea] http://www.eclac.org/brasil/publicaciones/sinsigla/ xml/0/36890/LCBRSR210RenatoBaumannBRICS.pdf.

Benson, B.L. (2012), "2009 Update of the World's Asparagus Production Areas, Spear Utilization and Production Periods" [en línea] http://www.actahort.org/books/950/950_9.htm-

Caputi Lélis, M.T., A. Moreira Cunha y M. Gomes de Lima (2012), "Desempeño de las exportaciones de China y el Brasil hacia América Latina, 1994-2009”, Revista CEPAL, N 106 (LC/G.2518-P), Santiago de Chile, abril.

Clemente, L. (2001), "Venezuela y los indicadores de competitividad", Documento de Trabajo, Proyecto Andino de Competitividad [en línea] http://www.cid.harvard.edu/archive/andes/documents/ workingpapers/indicators/indicators_venezuela.pdf.

De Pablo Valenciano, J. y M.A. Giacinti Battistuzzi (2013), ¿ Pierde posicionamiento España en las exportaciones de limón frente a sus competidores?, Almería, Fundación Cajamar.

(2012a), "The competitiveness of kiwifruit from the Southern hemisphere. 2012 Export forecast", Fresh Point Magazine, año IV, $\mathrm{N}^{\circ}$ 6, Milán, Editorial Ortofrutta Italiana, junio. (2012b), "Competitividad en el comercio internacional vs ventajas comparativas relevadas (VCR). Caso de análisis: Peras", Revista de Economía Agrícola, vol. 59, N 1, São Paulo, Instituto de Economía Agrícola [en línea] ftp://ftp.sp.gov.br/ ftpiea/rea/2012/rea1-4-12.pdf.

(2012c), "Competitividad en el comercio internacional vs ventajas comparativas reveladas (VCR): Ensayo sobre exportaciones de manzanas de América del Sur", Revista Mexicana de Economía Agraria y Recursos Naturales, $\mathrm{N}^{\circ} 6$, Chapingo, Universidad Autónoma de Chapingo.

De Pablo Valenciano, M.A. Giacinti Battistuzzi y J. Uribe (2012), "Revealed comparative advantage and competitiveness in pear", International Journal on Food System Dynamics, vol. 3, $\mathrm{N}^{\circ}$, Bonn, Universidad de Bonn [en línea] http://centmapress.ilb. uni-bonn.de/ojs/index.php/fsd/article/viewArticle/203.

Djolov, G. (2011), "The Hirschman-Herfindahl Index Reconsidered: Is there a Gini in the Bottle?", 20th EDAMBA Summer Research Academy, Sorèze, Francia.

Durán Lima, J.E. y M. Álvarez (2008), "Indicadores de comercio exterior y política comercial: Mediciones de posición y dinamismo comercial", Documentos de Proyectos, $\mathrm{N}^{\circ} 217$, Santiago de Chile, Comisión Económica para América Latina y el Caribe (CEPAL).

Dussel, E. (2001), "Un análisis de la competitividad de las exportaciones de prendas de vestir de Centroamérica utilizando los programas y la metodología CAN y MAGIC", serie Estudios y Perspectivas, $\mathrm{N}^{\circ} 1$ (LC/L.1520-P), México, D.F., sede subregional de la CEPAL en México, julio [en línea] http://www.econbiz.de/en/ search/detailed-view/doc/all/an\%C3\%A1lisis-competitividadlas-exportaciones-prendas-vestir-centroam\%C3\%A9ricautilizando-los-programas-metodolog\% $\mathrm{C} 3 \% \mathrm{ADa}$-can-magicdussel-peters-enrique/10001633811/?no_cache=1

Fadzlan, S. y S. Muzafar (2013), "Financial sector consolidation and competition in Malaysia: an application of the Panzar-Rosse method", Journal of Economic Studies, vol. 40, №3, Emerald Group Publishing Limited.

Gower, J. (1971), "A general coefficient of similarity and some of its properties", Biometrics, vol. 27, N 4, Washington, D.C., International Biometric Society.

(1967), "A comparison of some methods of cluster analysis", Biometrics, vol. 23, $\mathrm{N}^{\circ} 4$, Washington, D.C., International Biometric Society.
Hirschman, A.O. (1964), "The paternity of an index", American Economic Review, vol. 54, No 5, Nashville, Tennessee, American Economic Association.

Illescas, J. y C.F. Jaramillo (2011), "Export growth and diversification: the case of Peru", Policy Research Working Paper, $\mathrm{N}^{\circ}$ 5868, Washington, D.C., Banco Mundial, noviembre [en línea] http:// www-wds.worldbank.org/servlet/WDSContentServer/WDSP/ IB/2011/11/01/000158349_20111101083747/Rendered/PDF/ WPS5868.pdf

Jijena, R. (2003), "Las ondas largas en economía (ciclos Kondratiev) y la emergencia de un nuevo paradigma tecno-económico en Freeman y Louca", Barcelona, Universidad Abierta de Cataluña, inédito.

Mariscal, J. y R. Rivera (2007), "Regulación y competencia en las telecomunicaciones mexicanas", serie Estudios y Perspectivas, $\mathrm{N}^{\circ} 83$ (LC/MEX/L.780), México, D.F., sede subregional de la CEPAL en México, junio [en línea] http://www.eclac.org/ publicaciones/xml/7/29037/Serie\%2083.pdf.

Martínez Sánchez, J.M. (2001), "Las ondas largas de Kondratieff. Filosofía, política y economía", Laberinto, $\mathrm{N}^{\circ} 5$.

Matesanz, D. y A. Sánchez Díez (2005), "La asociación birregional Unión Europea América Latina: retórica y realidad del comercio y la inversión”, VII Reunión de Economía Mundial, Madrid, Facultad de Ciencias Económicas y Empresariales de la Universidad Complutense de Madrid.

Petit, L. (2012), "The economic detection instrument of the Netherlands Competition Authority: the competition index", NMa Working Paper, $\mathrm{N}^{\circ}$ 6, Netherlands Competition Authority [en línea] http://ssrn.com/abstract=1992774.

Ponce, M., M. Contreras y M. Vásquez (2007), "Exportación de madera aserrada de conífera chilena. Un análisis de competitividad", Maderas: Ciencia y Tecnología, vol. 9, $\mathrm{N}^{\circ} 1$, Concepción, Universidad del Bío-Bío.

Romo Murillo, R. (2007), "La competitividad exportadora de los sectores ambientalmente sensibles y la construcción de un patrón exportador sustentable en América Latina y el Caribe", México, D.F., junio [en línea] http://www.cepal.org/dmaah/ noticias/paginas/1/27731/romo_competitividad_IAS.pdf.

Sánchez Díez, A. y M.L. Villalobos Álvarez (2010), "El análisis de las relaciones comerciales de Centroamérica y la Unión Europea desde una perspectiva de economía política", Santiago de Compostela, mayo.

Sawaya Jank, M., M.F. Paes Leme y A. Meloni Nassar (2001), "Concentration and internationalization of Brazilian agribusiness exporters", International Food and Agribusiness Management Review, vol. 2, ํㅜ 3-4, Ámsterdam, Elsevier.

Schumpeter, J. (1944), “Análisis del cambio económico", Ensayos sobre el ciclo económico, México, D.F., Fondo de Cultura Económica.

Serlin, J. (2010), "Conocimiento de la gestión de las organizaciones: Sistemas complejos dinámicos inestables adaptativos", Tesis doctoral, Buenos Aires, Facultad de Ciencias Económicas de la Universidad de Buenos Aires [en línea] http://www.econ. uba.ar/www/servicios/Biblioteca/bibliotecadigital/bd/tesis_doc/ serlin.pdf.pdf.

Shimizu, T. (2009), "Structural changes in asparagus. Production and exports from Peru", IDE Discussion Paper, $\mathrm{N}^{\circ} 201$, Tokio, Instituto de las Economías en Desarrollo [en línea] http://iride. go.jp/dspace/bitstream/2344/843/1/201_shimizu.pdf.

Spilzinger, A.L. (2004), "Adaptación frente a la complejidad: Nuevo paradigma gerencial”, Revista VenEconomía, vol. 21, $\mathrm{N}^{\circ} 8$, mayo.

Toro, L.A. y J.A. Ruiz (2005), "Efectos potenciales de la inserción comercial de Venezuela en el ALCA", Venezuela en el ALCA: Entre realidades y fantasías, Mérida, Universidad de los Andes [en línea] http://www.mpl.ird.fr/crea/pdf/Libro\%20-\%20 ALCA\%20-\%20Venezuela.pdf. 